\title{
Improving of phosphorus use efficiency in Plant-Soil-System. A review
}

\author{
${ }^{1}$ Abou Seeda M.A., ${ }^{1}$ Yassen A.A., ${ }^{2}$ Abou El-Nour E.A. A. and ${ }^{1}$ Sahar M. Zaghloul \\ ${ }^{1}$ Plant Nutrition Dept., National Research Centre, 33 El Buhouth St., 12622 Dokki, Giza, Egypt. \\ ${ }^{2}$ Fertilization Tech. Dept., National Research Centre, 33 El Buhouth St., 12622 Dokki, Giza, Egypt. \\ Received: 10 March 2020/ Accepted 25 June 2020 / Publication date: 05 July 2020
}

\begin{abstract}
Phosphorus is an essential nutrient that is required for all major developmental processes and reproduction in plants. It is also a major constituent of the fertilizers required to sustain high-yield agriculture. Phosphorus form that can be assimilated by plants are suboptimal in most natural and agricultural ecosystems, and when phosphate is applied as fertilizer in soils, it is rapidly immobilized owing to fixation and microbial activity. Thus, cultivated plants can consumed approximately $20-30 \%$ of the applied phosphate fertilizers, and the rest is lost, eventually causing water eutrophication. Recent advances in the understanding of mechanisms by which wild and cultivated species adapt to lowphosphate stress and the implementation of alternative bacterial pathways for phosphorus metabolism have started to mallow the design of more effective breeding and genetic engineering strategies to produce highly phosphate-efficient crops, optimize fertilizer use, and reach agricultural sustainability with a lower environmental cost. Phosphorus dynamics in the soil plant system is a function of the integrative effects of Phosphorus transformation, availability, utilization caused by soil, rhizosphere, and plant processes. In this review, we outline the current advances in research on the complex network of plant responses to low-phosphorus stress and discuss some strategies used to manipulate genes involved in phosphate uptake, remobilization, and metabolism to develop low-phosphate-tolerant crops, which could help in designing crops that are more efficient.
\end{abstract}

Keywords: Phosphorus Dynamics-phosphorus use efficiency- management of P- uptake

\section{1- Introduction}

With increasing demand of agricultural production and as the peak in global production will occur in the next decades, phosphorus $(\mathrm{P})$ is receiving more attention as a nonrenewable resource Cordell et al., (2009); Gilbert, (2009). One unique characteristic of Phosphorus is its low availability due to slow diffusion and high fixation in soils. All of this means that Phosphorus can be a major limiting factor for plant growth. Applications of chemical Phosphorus fertilizers and animal manure to agricultural land have improved soil $\mathrm{P}$ fertility and crop production, but caused environmental damage in the past decades. Maintaining a proper Phosphorus -supplying level at the root zone can maximize the efficiency of plant roots to mobilize and acquire $\mathrm{P}$ from the rhizosphere by an integration of root morphological and physiological adaptive strategies. Furthermore, Phosphorus uptake and utilization by plants plays a vital role in the determination of final crop yield. A holistic understanding of Phosphorus dynamics from soil to plant is necessary for optimizing Phosphorus management and improving Phosphorus -use efficiency, aiming at reducing consumption of chemical Phosphorus fertilizer, maximizing exploitation of the biological potential of root/rhizosphere processes for efficient mobilization, and acquisition of soil Phosphorus by plants as well as recycling Phosphorus from manure and waste. Taken together, overall Phosphorus dynamics in the soil plant system is a function of the integrative effects of Phosphorus transformation, availability, and utilization caused by soil, rhizosphere, and plant processes. This Update focuses on the dynamic processes determining Phosphorus availability in the soil and in the rhizosphere, Phosphorus mobilization, uptake, and utilization by plants. It highlights recent advances in the understanding of the Phosphorus dynamics in the soil/rhizosphere-plant continuum.

\section{2- Phosphorus Dynamics in soil}

\section{2-1 -Soil Phosphorus Transformation}

Soil P exists in various chemical forms including inorganic Phosphorus and organic Phosphorus. These Phosphorus forms differ in their behavior and fate in soils Hansen et al., (2004); Turner et al., (2007).

Corresponding Author: Abou Seeda M.A., Plant Nutrition Dept., National Research Centre, 33 El Buhouth St., 12622 Dokki, Giza, Egypt. E-mail: mabouseeda@gmail.com 
Inorganic Phosphorus usually accounts for 35\% to 70\% of total Phosphorus in soil (Harrison, 1987). Primary Phosphorus minerals including apatites, strengite, and variscite are very stable, and the release of available Phosphorus from these minerals by weathering is generally low to meet the crop demand though direct application of phosphate rocks (i.e. apatites) has proved relatively efficient for crop growth in acidic soils. In contrast, secondary Phosphorus minerals including calcium, iron, and aluminum phosphates which vary in their dissolution rates, depending on size particles and soil $\mathrm{pH}$ Pierzynski et al., (2005); Oelkers and Valsami-Jones, (2008). With increasing soil pH, solubility of Fe and $\mathrm{Al}$ phosphates increases but solubility of $\mathrm{Ca}$ phosphate decreases, except for $\mathrm{pH}$ values above 8 Hinsinger, (2001). Phosphorus adsorbed on various clays and Al/Fe oxides can be released by desorption reactions. All these Phosphorus forms exist in complex equilibrium with each other, representing from very stable, sparingly available, to plant-available Phosphorus pools such as labile Phosphorus and solution Phosphorus Fig. (1).

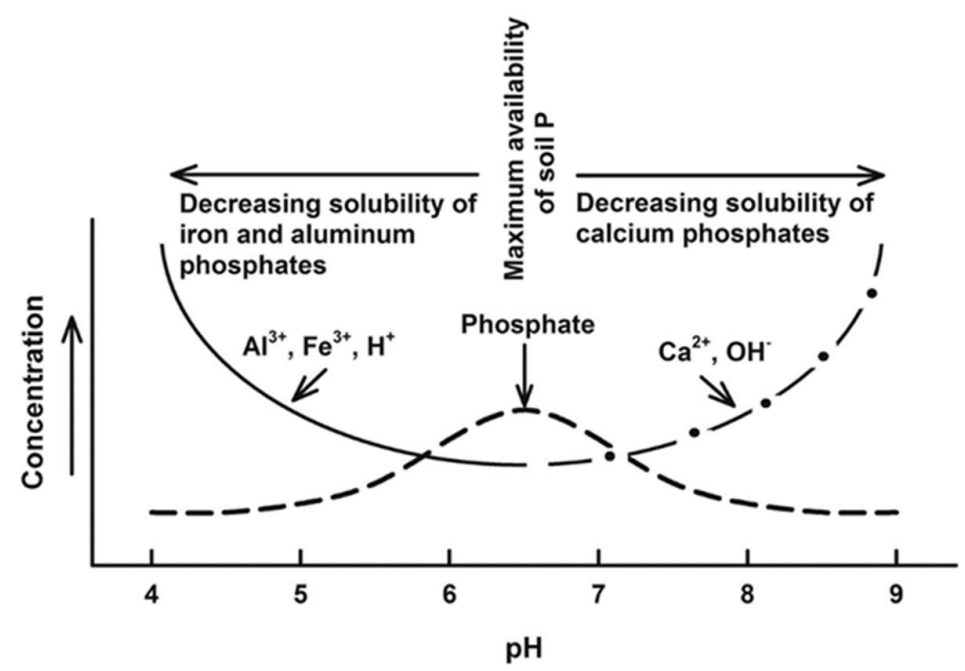

Fig. 1: Diagram illustrated general qualitative representation of soil phosphorus availability as impacted by $\mathrm{pH}$ after Price (2006)

In acidic soils, $\mathrm{Al} / \mathrm{Fe}$ oxides and hydroxides, such as gibbsite, hematite, and goethite can dominantly adsorb phosphorus Parfitt, (1989). Phosphorus adsorbed on the surface of clay minerals and $\mathrm{Fe} / \mathrm{Al}$ oxides. The nonprotonated and protonated bidentate surface complexes may coexist at $\mathrm{pH} 4$ to 9, while protonated bidentate inner sphere complex is predominant under acidic conditions Luengo et al., (2006); Arai and Sparks, (2007). Clay minerals and Fe/Al oxides have large specific surface areas, which provide large number of adsorption sites. The adsorption of soil phosphorus can be enhanced with increasing ionic strength. With further reactions, phosphorus may be occluded in nanopores that frequently occur in $\mathrm{Fe} / \mathrm{Al}$ oxides, and thereby become unavailable to plants Arai and Sparks, (2007).

In neutral-to-calcareous soils, phosphorus retention is dominated by precipitation reactions Lindsay et al., (1989), although phosphorus can also be adsorbed on the surface of Ca carbonate Larsen, (1967) and clay minerals Devau et al., (2010). Phosphate can precipitate with Ca, generating di-calcium phosphate $(D C P)$ that is available to plants. Ultimately, $D C P$ can be transformed into more stable forms such as Octocalcium phosphate and hydroxyapatite $(H A P)$, which are less available to plants particularly under alkaline condition Arai and Sparks, (2007). HAP accounts for more than $50 \%$ of total inorganic phosphorus in calcareous soils from long-term fertilizer experiments. HAP dissolution increases with decrease of soil pH Wang and Nancollas, (2008) Fig, (2).

Acidification rhizosphere may be an efficient strategy to mobilize soil phosphorus from calcareous soil. Organic phosphorus generally accounts for $30 \%$ to $65 \%$ of the total P in soils Harrison, (1987). Soil organic phosphorus mainly exists in stabilized forms as inositol phosphates and phosphonates, and active forms as orthophosphate diesters, labile orthophosphate monoesters, and organic polyphosphates Turner et al., (2002); Condron et al., (2005). The organic phosphorus can be released through mineralization processes mediated by soil organisms and plant roots in association with phosphatase secretion. These processes are highly influenced by soil physicochemical properties 
of soils; transformation of organic phosphorus forms has a great influence on the overall bioavailability of Phosphorus in soil (Turner et al., 2007).

Therefore, Phosphorus availability in soil is extremely complex and needs to be systemically evaluated because it is highly associated with Phosphorus dynamics and transformation among various Phosphorus pools Fig. (3).
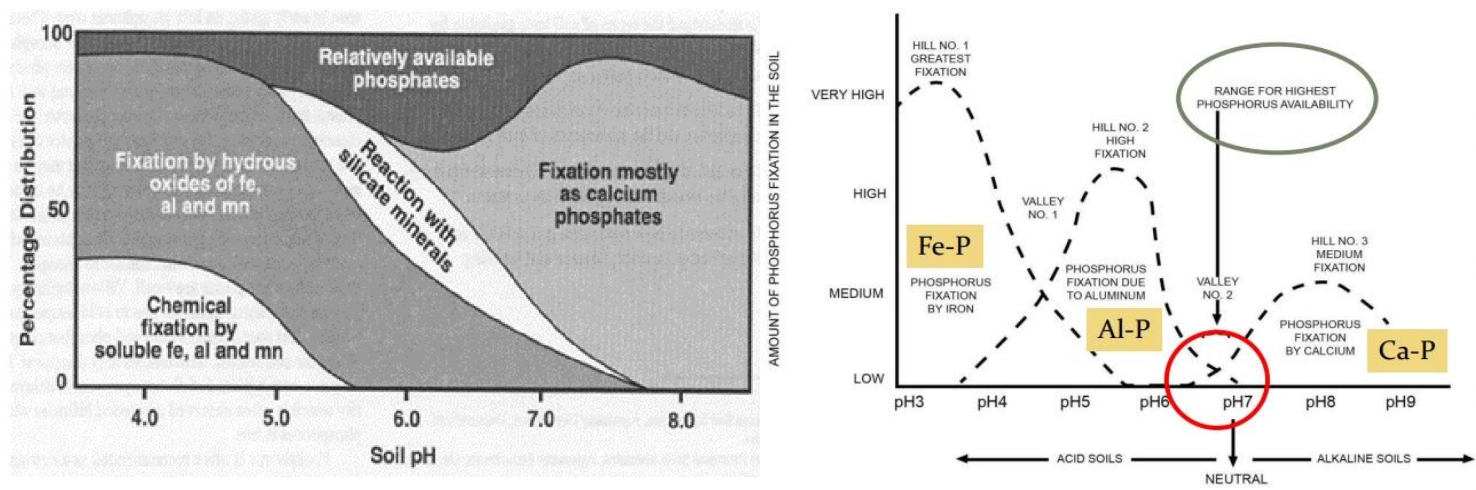

Fig. 2: Diagram illustrated soil phosphorus availability across $\mathrm{pH}$ ranges

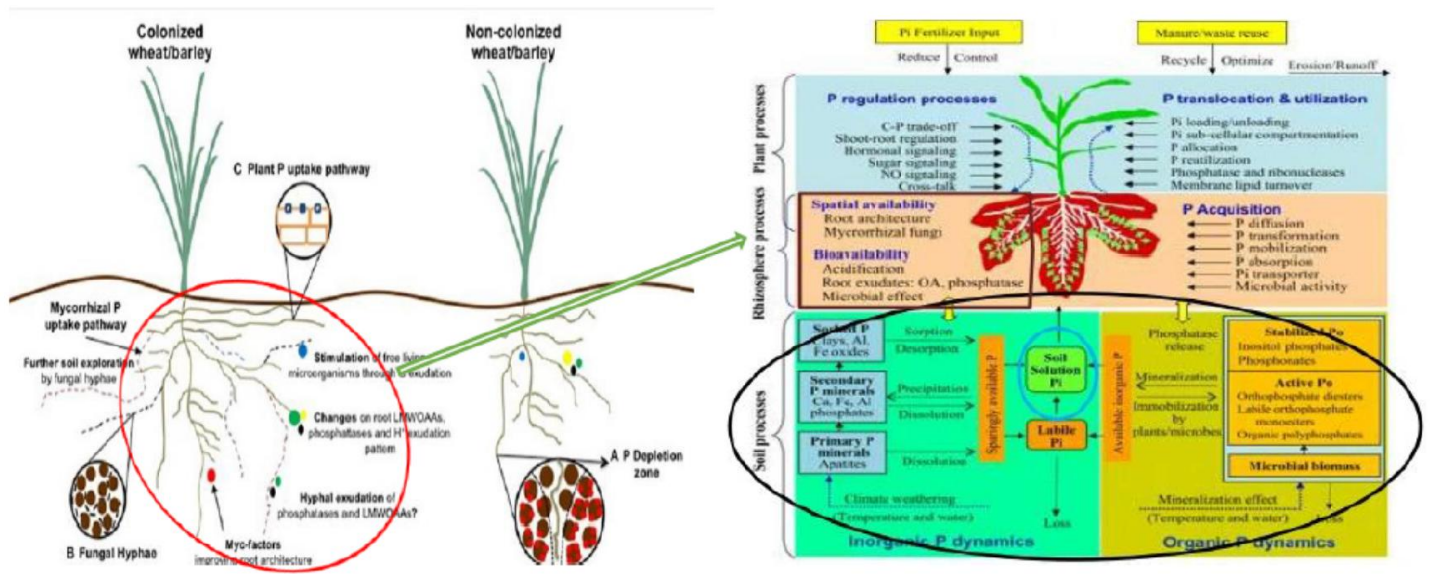

Fig. 3: Illustrates soil phosphorus dynamics in soil-Rhizosphere-plant relationships

Chemical Fertilizer Phosphorus in Soil The modern terrestrial Phosphorus cycle is dominated by agriculture and human activities Oelkers and Valsami-Jones, (2008). The concentration of available soil inorganic-phosphorus (Pi) not exceeds than $10 \mathrm{mM}$, Bieleski, (1973), which is much lower than that in plant tissues where the concentration is approximately 5 to $20 \mathrm{mM}$ (Pi) Raghothama, (1999). Fertilizers-P application are needed particularly under low availability phosphorus in soils to improve growth and yield production. Available forms of phosphate fertilizers are monocalcium phosphate $(M C P)$ and monopotassium phosphate $(M P P)$, however $M C P$ can significantly affect soil physicochemical characteristics. Benbi and Gilkes, (1987) application of $M C P$ are quickly converted to phosphate, and $D C P$, and eventually forms a Phosphorus -saturated patch. Three different reaction zones are occurred, including direct, precipitation, and adsorption reaction zones. Direct reaction zone is very acidic ( $\mathrm{pH}=1.0-1.6)$, which enhancing the mobility of soil metal ions. These metal ions react with inorganic - Phosphorus causing further precipitation. However, amorphous of Fe-P and Al-P can be partly available to plants. In calcareous soil, new complexes of $M C P$ and $D C P$ can be formed and with time, $D C P$ is gradually transformed into more stable forms of tri-Ca phosphates $(T C P)$, is dominant in the outer zone due to low concentration of inorganic -P adsorption reaction by soil Moody et al., (1995) Fig.(2). In contrast, the application of monopotassium phosphate has little influence on soil physical and chemical properties Lindsay et al., (1962). Therefore, equivalent amount of Phosphorus 
fertilizer types $(M C P$ and $D C P)$ to soil may be an efficient strategy for rational use of chemical phosphorus fertilizer.

\section{2-2 Organic matter as a source of phosphorus}

Prolonged of organic matter $(O M)$ as a source of nutrients elements for enhancing soils fertility were used. With development the industries of mineral fertilizers, using of organic matter has decreased Muraishi et al. (2011). However, due to the growing pressures of conforming to environmental quality standards Carvajal-Muoz and Carmona-Garcia (2012), and increasing the costs of fertilizers ANDA (2016), there is an interest for using, organic matter as a source of nutrient in agriculture soil. The quality of organic matter can vary depending on type, treatments, and its maturity (composting presses). Manure from livestock production (cow manure) contains high concentrations of available nutrients Hariadi et al. (2016), mainly, nitrogen, phosphorus and sulfur (S) Muraishi et al. (2011), however, organic matter from poultry production (chicken and turkey) which contains high concentrations of potassium and phosphorus Pinto et al. (2012). The process of organic composting is special technique that reduces some pathogens and enhances nutrient availability to plants. Application of limestone and gypsum through composting processes is an alternative of enrichment, for increasing nutrient availability Ramos et al. (2013). However, this technique needs to be more thoroughly studied because of the possible increase of Phosphorus adsorption in soil and a subsequent imbalance between the bases of $\mathrm{Mg}, \mathrm{Ca}, \mathrm{K}$, with the formation of percolating sulfates in soil Ramos et al. (2013). Furthermore, farmers should pay attention to the quality and quantity of animal manure used as a source of nutrients in soil. Both quality and quantity can cause an excessive input of nutrients leading to soil as well as and groundwater contamination Min et al. (2012).

Organic matter applied to agricultural lands for enhancing the fertility status particularly phosphorus, is very variable and nearly $70 \%$ of total-P in manure is labile, which inorganic phosphorus were ranged between $50 \%$ to $90 \%$ (Dou et al., 2000). Also contains large amounts of organic phosphorus, such as phospholipids and nucleic acids (Turner and Leytem, 2004), which can be released and increase soil the inorganic phosphorus contents through mineralization. On the other hand, small molecular of organic acids created from mineralization of humic substances from manure can increase the availability of Ca phosphate, especially for citrate, which was more efficiency (Martins et al., 2008). Adsorption of phosphorus in soil can be greatly reduced through applying organic substances. The humic acids contain large numbers of negative charges, carboxyl and hydroxyl groups, which strongly compete for the adsorption sites with inorganic phosphorus. Application of organic matter can affected on the acidity of soil, furthermore increasing phosphorus availability. However, mechanisms of organic matter added encourage phosphorus alternation between inorganic and organic phosphorus in soil, further investigation still needed.

\section{3- Phosphorus Dynamics in the Rhizosphere}

Rhizosphere is the accurate zone that interacts between plants, soils, and microorganisms. Plant roots network can greatly modify the rhizosphere environment through their various physiological activities, particularly the exudation of organic compounds such as mucilage, organic acids, phosphatases, and some specific signaling substances, which are key drivers of various rhizosphere processes Fig.(4).

Chemical and biological processes in rhizosphere not only determine mobilization and acquisition of soil nutrients as well as microbial dynamics, but also control nutrient use efficiency, and furthermore abjectly influence crop production. Hinsinger et al., (2009); Richardson et al., (2009); Wissuwa et al., (2009); Zhang et al., (2010).

Bioavailability of phosphorus can be depleted rapidly via root uptake particularly in the rhizosphere, creating in a gradient of phosphorus concentration in a radial direction away from the root surface. Phosphorus content in soil usually exceeding the plant requirements, however, low mobility of phosphorus can restrict its availability to plants. Soluble phosphorus in soil solution particularly in the rhizosphere should be replaced 20 to 50 times per day by phosphorus delivery from bulk soil to the rhizosphere to meet plant demand Marschner, (1995). Therefore, phosphorus dynamics in the rhizosphere are mainly controlled by plant root growth and function, and highly related to physical and chemical properties of soil Neumann and Römheld, (2002). Two key processes dominantly control the availability of phosphorus due to low solubility, mobility, and high fixation in soil: (a) spatial 
availability and acquisition of phosphorus in terms of plant root architecture as well as mycorrhizal association, and $(\boldsymbol{b})$ bioavailability and acquisition of phosphorus based on the rhizosphere chemical and biological processes Fig. (3).

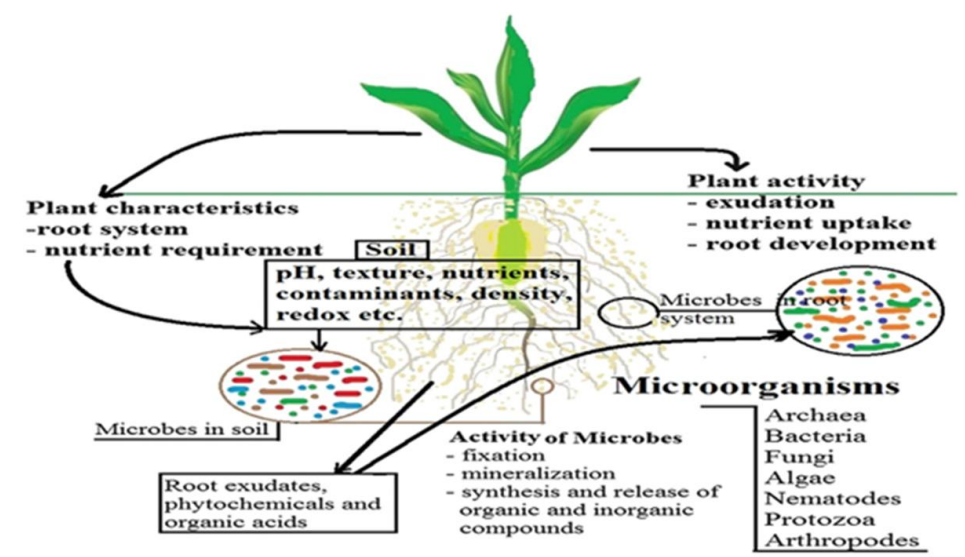

Fig. 4: Diagram illustrated chemical and biological processes in rhizosphere

\section{3-1 Controlling of inorganic phosphate}

Uptake of available inorganic phosphorus through coordinated achievement of several inorganic phosphorus transporters, which is greatly influenced by the root exploration capacity. Inorganic phosphorus uptake and scavenging capacity, which is determined mainly by the root system architecture; and integrated with microbes, such as AM fungi, that assist the plant in scavenging inorganic phosphorus from the soil Fig.(4). PAE (Phosphorus Acquisition Efficiency) is affected by other root traits that increase inorganic phosphorus availability in the soil solution, including the type and rate of efflux of organic acids (OAs) and phosphatases from the root.

\section{3-1-1- Transporters of Inorganic Phosphate}

Plants subjected to low inorganic phosphorus inducible high-affinity and constitutive low-affinity inorganic phosphorus uptake systems. Phosphate Transporter genes, (Pht) that encode inorganic phosphorus transporters have been characterized in detail in Arabidopsis and grouped into four families: Pht1, Pht2, Pht3, and Pht4 Raghothama and Karthikeyan and Karthikeyan (2005.) Fig. (5).

Conspicuous advances has also been made for characterizing inorganic phosphorus transporters in several economically important plant species, including tomato (Solanum lycopersicum), potato (Solanum tuberosum), soybean (Glycine max), rice (Oryza sativa), barley (Hordeum vulgare), and maize (Zea mays) Ai et al. (2009), Fan et al. (2013), Glassop et al. (2007), Nagy, et al. (2005), (2007), Paszkowski et al. (2002), Qin et al. (2012), Rae et al. (2003), Sun et al. (2012), Takabatake et al. (1999), Versaw and Harrison (2002), Wang et al. (2011). Inorganic phosphorus transporters encoded by members of the Pht 1 gene family, which are predominantly expressed in epidermal cells and in the outer cortex of the root, have been identified as mediators of inorganic phosphorus uptake at the rootsoil interface particularly when inorganic phosphorus is limited Mudge et al. (2002), Sch et al (2004) Fig. (5). These proteins are part of the so-called direct inorganic phosphorus uptake pathway and transport phosphorus as inorganic phosphorus anions, mainly $\mathrm{H}_{2} \mathrm{PO}_{4}{ }^{-1}$ and $\mathrm{HPO}_{4}^{-2}$, against a concentration gradient between the soil solution (which typically contains $0.1-10 \mu \mathrm{M}$ inorganic-P) and the cytoplasm of the root epidermal cell (which typically contains 5-10 mM inorganic- P) Raghothama and (2005). Fig. (3). 


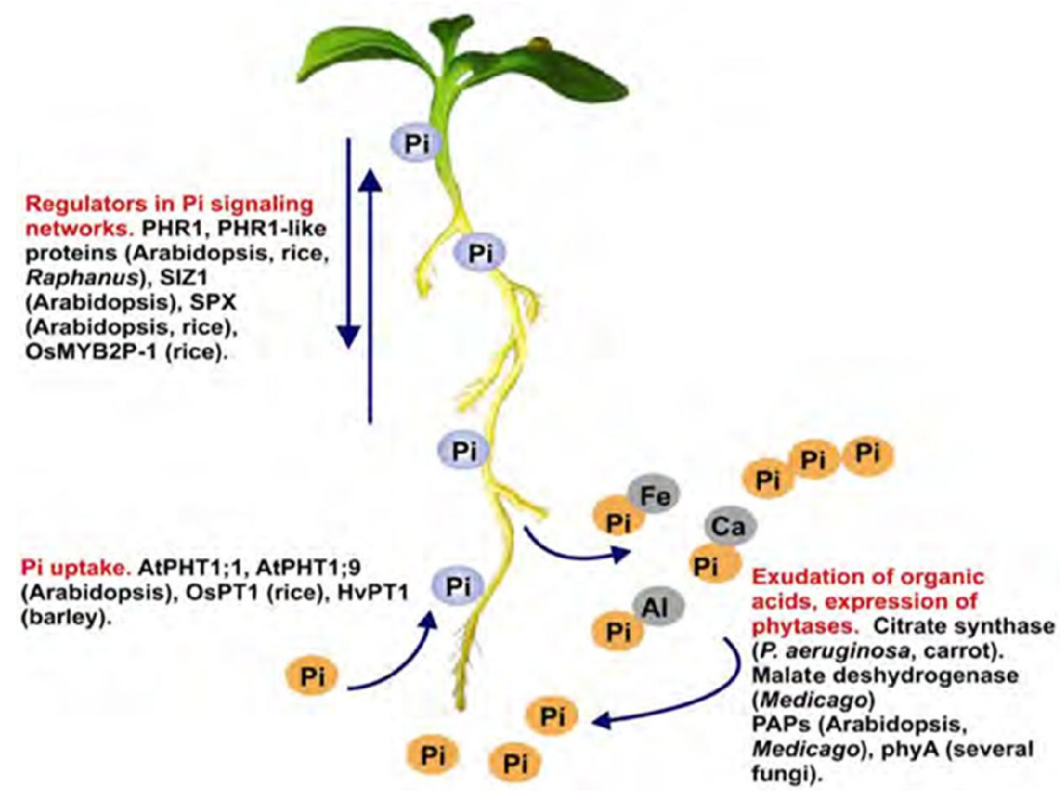

Fig. 5: Illustrates Schematic representation of the phosphorus-scavenging, uptake and assimilation processes targeted by genetic engineering strategies. Proteins involved in phosphate scavenging, transport, or regulatory mechanisms and genetically manipulated for enhancing inorganic phosphorus uptake and release from insoluble compounds.

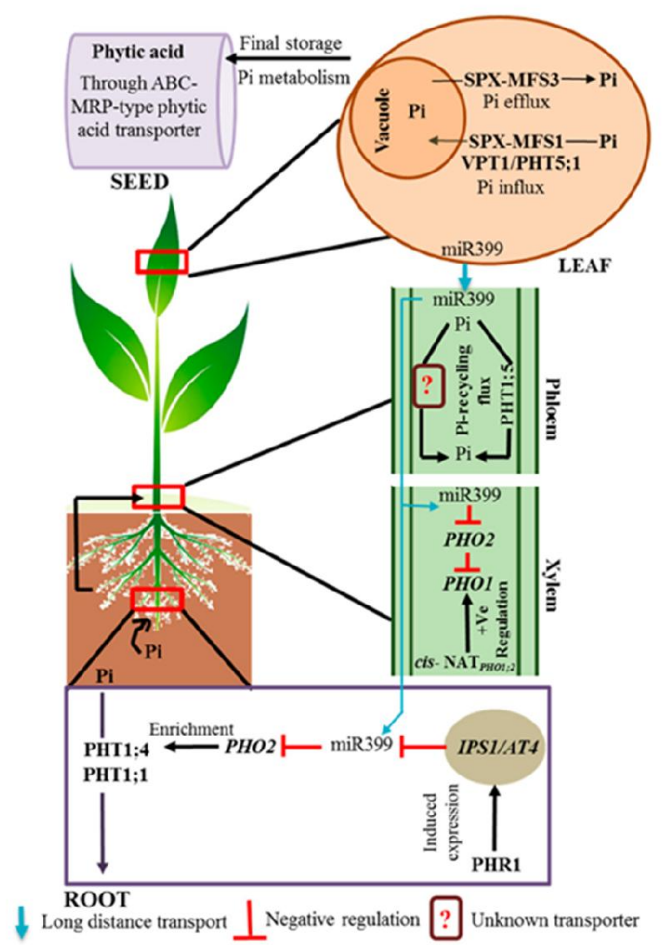

Fig. 5: PHF1 Facilitates PHT1; 2-CFP Targeting through the ER Compartment. Transient protein expression in N.benthamiana epidermal cells analyzed by confocal microscopy $48 \mathrm{~h}$. after infiltration. Transient expression of PH1; 2-CFP alone to a low (A) or High level (D) and together with YFP-PHF1 (G to $\mathbf{L}$ ). (G to I), show localization in the ER (arrowheads indicate post-ER compartments). (J) to (L) show PHT1;2-CFP delivery to plasma at cell periphery.(M) to(O) show transient coexpression of YFPPHF1 (J) with ER marker KDEL-DsRed (K). Bras $=10 \mathrm{~mm}$, except in $(\mathrm{J})$ to $(\mathrm{L})$, where bars $=50 \mu \mathrm{m}$ 


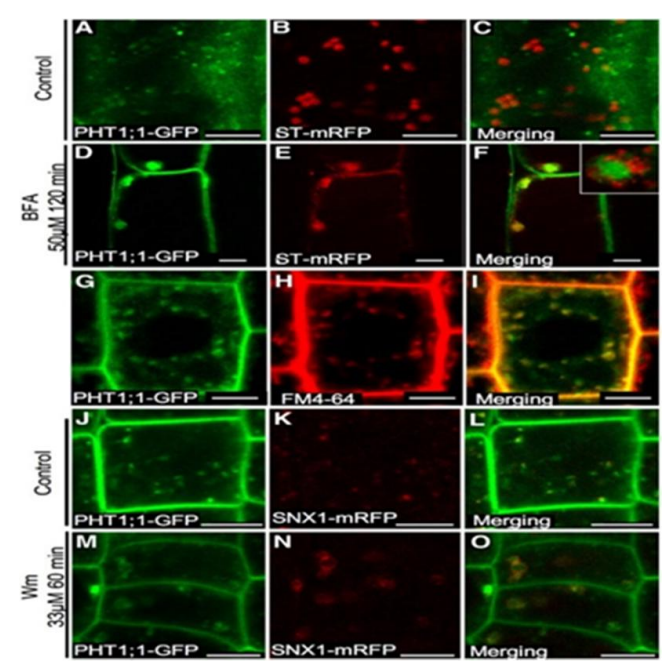

Fig. 6: Overview of phosphate (Pi) transport in Arabidopsis plants after Sudhakar Srivastava et al. (2018)

Sudhakar Srivastava et al. (2018) reported that the transport route is shown in four parts: uptake from soil to roots, transport from roots to shoots, unloading in shoots and subcellular organelles, and transport to seeds in the form of phytic acid Fig. (6). The high-affinity Pi (PHT1) family (PHT1;1 and PHT1;4) of transporters plays a major role in Pi uptake from soil to roots. The PHO1 protein increases root-Pi xylem loading, whereas PHT1;5 plays a key role in the translocation of Pi from shoots to roots, and Pi mobilization to reproductive organs. In plant cell, vacuoles act as the primary intracellular compartments for Pi storage, and SPX-MFS1 and SPX-MFS3/PHT5;1 mediate vacuolar Pi influx and efflux, respectively. Furthermore, $\mathrm{Pi}$ is metabolized and transported from leaves to seeds in the form of phytic acid by the ABC-MRP-type phytic acid transporter. The levels of PHT1, PHO1 and PHO2 transporters are regulated by miR399 and cis-NATPHO1;2 in xylem, and by miR399 and IPS1/AT4 in roots. ABC-MRP, ATP binding cassette-multidrug resistance-associated protein; AT4, Arabidopsis thaliana 4; IPS1, induced by phosphate starvation 1; cis-NATPHO1;2, cis-natural antisense transcript phosphate transporter 1;2; PHT, high-affinity phosphate transporter; PHR1, phosphate starvation response 1; Pi, phosphate; PHO1, phosphate transporter 1; SPX-MFS3, SYG1/PHO81/XPR1 major facility superfamily 3; SPX-MFS1, SPX major facilitator superfamily 1; VPT1, vacuolar phosphate transporter 1. Figure 1. Overview of phosphate (Pi) transport in Arabidopsis plants. The transport route is shown in four parts: uptake from soil to roots, transport from roots to shoots, unloading in shoots and subcellular organelles, and transport to seeds in the form of phytic acid. The high-affinity Pi (PHT1) family (PHT1; 1 and PHT1; 4) of transporters plays a major role in Pi uptake from soil to roots. The PHO1 protein increases root-Pi xylem loading, whereas PHT1;5 plays a key role in the translocation of Pi from shoots to roots, and Pi mobilization to reproductive organs. In plant cell, vacuoles act as the primary intracellular compartments for Pi storage, and SPX-MFS1 and SPX-MFS3/PHT5;1 mediate vacuolar Pi influx and efflux, respectively. Furthermore, $\mathrm{Pi}$ is metabolized and transported from leaves to seeds in the form of phytic acid by the ABC-MRP-type phytic acid transporter. The levels of PHT1, PHO1 and PHO2 transporters are regulated by miR399 and cis-NATPHO1; 2 in xylem and by miR399 and IPS1/AT4 in roots. ABC-MRP, ATP binding cassette-multidrug resistance-associated protein; AT4, Arabidopsis thaliana 4; IPS1, induced by phosphate starvation 1; cis-NATPHO1;2, cis-natural antisense transcript phosphate transporter 1;2; PHT, high-affinity phosphate transporter; PHR1, phosphate starvation response 1; Pi, phosphate; PHO1, phosphate transporter 1; SPX-MFS3, SYG1/PHO81/XPR1 major facility.

Although the majority of Pht1 transcripts have been located in root epidermal cells and root hairs, many of them have also been detected in leaves, stems, cotyledons, pollen grains, seeds, flowers, and potato tubers, suggesting their involvement not only in inorganic phosphorus uptake by roots but also in internal root-to-shoot distribution Ai, et al. (2009). Chiou and, Harrison (2001). Davies et al. (2002), Fan et al. (2013), Nagy et al. (2006). Qin et al. (2012). In soybean, 14 members of the Pht1 family encode high-affinity inorganic phosphorus transporters predominantly expressed in roots under low 
inorganic phosphorus conditions Fan et al. (2013). In Medicago truncatula, 5 transporters encoded by Pht1 genes are inducible by low inorganic phosphorus, of which MtPT1 (Medicago truncatula PHOSPHATE TRANSPORTER 1) and MtPT2 play an important role in inorganic phosphorus uptake; MtPT4 plays a role in inorganic phosphorus translocation from mycorrhizal fungi into the roots Harrison et al. (2002), Liu et al (2008). Xiao et al. (2006). In rice, the Pht1 gene family is composed of 13 members (OsPT1-13); 4 of www. These (OsPT2, OsPT3, OsPT6, and OsPT7) are highly expressed in inorganic phosphorus deprived roots, but several (such as OsPT6) apparently play a dual role in inorganic phosphorus uptake from the soil and inorganic phosphorus translocation inside the plant $\mathrm{Ai}$, et al. (2009). Goff et al. (2002), Paszkowski et al. (2002). In maize, five Pht1 genes (ZmPht1;1-5) are induced by inorganic phosphorus limitation not only in roots but also in other tissues, such as young and old leaves, anthers, pollen, and seeds Nagy et al. (2006).

Therefore, at least some members of the Pht 1 gene family play an important role in inorganic phosphorus uptake from the soil solution, particularly when this nutrient is present in limiting amounts. In contrast to Pht1 genes, members of the Pht2, Pht3, and Pht 4 gene families have been associated mainly with inorganic phosphorus distribution within subcellular compartments, and their gene products are specifically located in the plastid inner membrane, mitochondrial inner membrane, and Golg compartment, respectively Cubero et al. (2009), Guo et al. (2008). Versaw and Harrison (2002) Fig. (7).

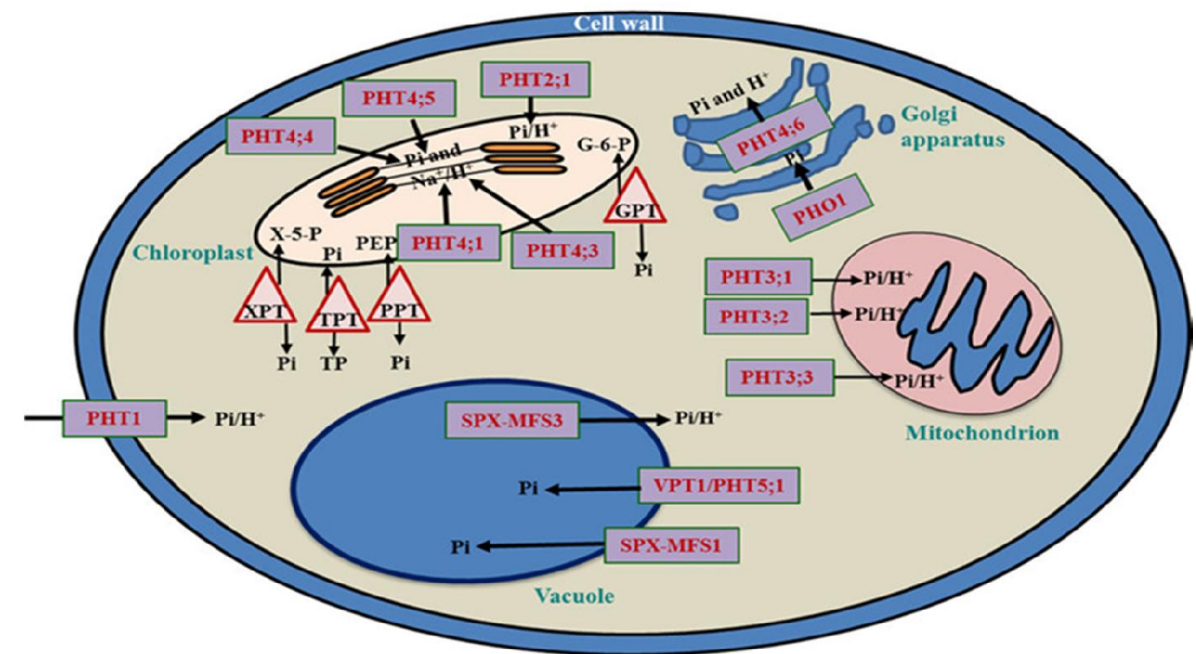

Fig. 7: Illustrates Subcellular localization of phosphate (Pi) transporters and translocators in Arabidopsis cells. PHT1, PHT2, PHT3, and SPX-MFS3 are proton-coupled Pi transporters. VPT1/PHT5; 1 and SPX-MFS1 function as Pi channels for Pi influx from the cytoplasm into the vacuoles, whereas SPX-MFS3 mediates Pi efflux from the vacuoles into cytoplasm. PHT4 proteins mediate $\mathrm{Na}+/ \mathrm{H}+$-dependent Pi transport from the cytosol to the chloroplasts or Golgi. PHO1 localizes to Golgi membranes and mediates Pi transport without an $\mathrm{H}+$ gradient across the membrane. Among the PHT2 family members, only PHT2.1 was functionally characterized as a Pi importer in the chloroplast envelope. AtPHT3 genes encode a small family of mitochondrial Pi transporters. These translocators mediate Pi transport in the exchange of various substrates. GPT, glucose 6-phosphate (G6-P) / (Pi) trans locator; PPT, phosphoenolpyruvate (PEP)/Pi translocator; TPT, triose phosphate (TP)/Pi translocator; XPT, xylulose-5-phosphate (X-5-P)/Pi translocator. PHT, high-affinity phosphate transporter; SPX-MFS3, SYG1/PHO81/XPR1 major facility superfamily 3; SPX-MFS1, SPX major facilitator superfamily 1; VPT1, vacuolar phosphate transporter 1; Black arrows show the influx and efflux of Pi in the vacuole, mitochondrion, Golgi apparatus, and chloroplast through the regulation of various PHT members.

In Arabidopsis, the low-affinity transporter PHT2; 1, encoded by a member of the Pht2 family, is located in chloroplasts, and a pht2; 1 mutation reduces inorganic phosphorus transport into the chloroplast and decreases inorganic phosphorus allocation throughout the whole plant. However, the pht2;1 mutant is still viable, suggesting alternative mechanisms for inorganic phosphorus import into chloroplasts Versaw and Harrison ( 2002). Although the Pht2 family of transporter genes is also present 
in Medicago truncatula and potato, compelling evidence of its function in these plants is still lacking. Mitochondrial inorganic-P transporter genes have also been identified in soybean, maize, and rice Takabatake et al. (1999); however, as is the case for chloroplast transporters, further investigation is needed to determine their physiological function and to evaluate their potential as biotechnological tools.

The concerted action of inorganic phosphorus transporters ensures inorganic phosphorus distribution to specific tissues, cells, and organelles. From an agronomic point of view, the ubiquity, diversity, and tissue distribution of inorganic-P transporters ensure that photosynthesis and respiration operate normally even under high stress conditions to sustain growth and reproduction Fig.(7). Therefore, engineered alterations of the expression of different inorganic phosphorus transporters represent an opportunity to optimize uptake and proper distribution of inorganic-P within a plant to improve yield.

\section{4- Spatial Availability and gaining Soil Phosphorus}

\section{4-1 Roots network}

Plants are able to respond to phosphorus starvation by changing their root architecture, including root morphology, topology, and distribution patterns. Increases in root/ shoot ratio, root branching, root elongation, root topsoil foraging, and root hairs are commonly observed in phosphorus deficient plants, while the formation of specialized roots such as cluster roots occurs in a limited number of species Lynch and Brown, (2008); Vance, (2008). Phosphorus deficiency has been shown to reduce growth of primary roots and enhance length and density of root hairs and lateral roots in many plant species (Lo'pez- Bucio et al., 2003; Desnos, (2008).

The phosphorus efficient genotypes of common bean (Phaseolus vulgaris) have more shallow roots in the topsoil where there are relatively high contents of P resources (Lynch and Brown, 2008). Some plant species, for example white lupin (Lupinus albus); can develop cluster roots with dense and determinative lateral roots, which are covered by large numbers of root hairs (Lambers et al., 2006; Vance, 2008).

\section{4-2 Regulation of Roots network.}

Significant advance has been made in dissecting the mechanisms underlying changes in root system architecture in response to inorganic phosphorus deficiency, particularly in Arabidopsis. In wild and cultivated plants, including Arabidopsis, maize, rice, and tomato, inorganic phosphorus availability alters root traits by modulating the developmental programs that control lateral root primordium initiation and emergence, primary and lateral root growth, the angle of lateral root growth, and the density and elongation rate of root hairs L'opez-Bucio et al. (2003), (2002), P'erez-Torres et al. (2008), Williamson et al. (2001). The availability of inorganic phosphorus on root development is complex, species specific, and genotype dependent and involves crosstalk between different hormone-signaling pathways. Signaling pathways activated by auxins, ethylene, Cytokinins, gibberellins, strigolactone, jasmonic acid, nitric oxide, sugars, or the redox status of the root meristem play an important role in the root system architecture responses to low inorganic phosphorus availability Chiou and Lin (2011), Ha and Tran (2014.). The first visible event in Arabidopsis plants suffering inorganic phosphorus deficiency is a strong reduction of primary root growth, which occurs rapidly after transfer to a low inorganic phosphorus medium and is followed by an arrest of cell division and loss of the quiescent center identity S'anchez-Calder et al. (2006),(2005), Svistoonoff et al. (2007) simultaneously, the formation of abundant lateral roots and root hairs expressing high levels of inorganic phosphorus transporters and phosphatases is enhanced by inorganic phosphorus limitation $\mathrm{S}^{\prime}$ anchez-Calder et al. (2005), L'opez-Bucio et al. (2003), (2002) (2005), Nacry et al. (2005). P'erez-Torres et al. (2008) Fig. (8). 


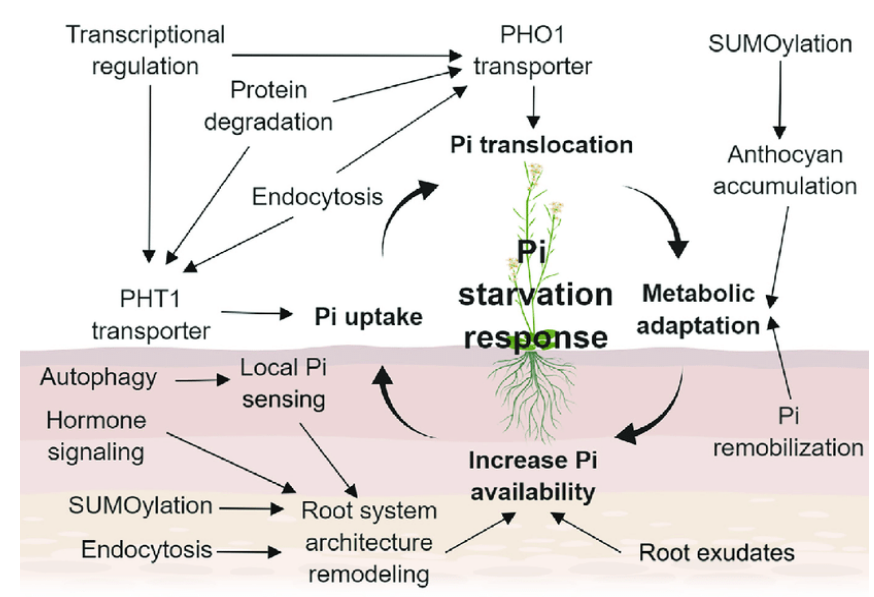

Fig. 8: Modulation of the Phosphate Starvation Response (PSR) through Ubiquitination in Plants after Wenbo Pan, et al. (2019)

Wenbo Pan, et al. (2019) reported that, plants have evolved several ubiquitination-related strategies to overcome inorganic phosphate (Pi)-limiting conditions. Activation of autophagy by the local Pi sensor PHOSPHATE DEFICIENCY RESPONSE 2 (PDR2) and LOW PHOSPHATE ROOT 1/1 $(L P R 1 / 2)$ assists $\mathrm{Pi}$ sensing in the root tip to relieve endoplasmic reticulum (ER) stress under Pi starvation. PHOSPHATE TRANSPORTER 1s (PHT1s), which are Pi transporters responsible for Pi uptake, are regulated by ubiquitination-mediated degradation and endocytosis to precisely modulate their protein level and subcellular localization. Transcription factors responsible for the activation of PHT1s and PHOPSHATE 1 (PHOI) and the interacting proteins of these transcription factors are regulated by ubiquitination under different Pi supplement conditions. PHO1 itself is regulated by ubiquitination related degradation to reduce its level under Pi-sufficient conditions. SUMOylation

Different mechanisms explain the modulation of primary root growth and enhancing lateral root and root hair formation in response to low inorganic phosphorus conditions, through changes in auxin transport and an increase in sensitivity to auxin. An increase in sensitivity to auxin in pericycle cells has been proposed to be responsible for increased lateral root initiation and emergence in plants grown under inorganic phosphorus deficiency L' opez-et al. (2002). P'erez-Torres et al. (2008.). This response was directly related to the findings that the expression of the Arabidopsis auxin receptor TIR1 (Transport Inhibitor Response 1) is higher in inorganic phosphorus deficient plants than in plants grown under sufficient conditions $\mathrm{P}^{\prime}$ erez-Torres et al. (2008).

The increased lateral root formation mediated by TIR1 in response to inorganic phosphorus deficiency requires the presence of the ARF7 (Auxin Response Factor 7) and ARF19 (transcription factors), which transduce and, enhancing auxin response into the formation of new lateral roots $\mathrm{P}^{\prime}$ erezTorres et al. (2008). Fig. (8). However, accumulation of auxin plays an important role for increasing the emergence of preformed lateral root primordial Nacry et al. (2005), Guo et al. (2011). Recently the expansins cell wall proteins that influence cell division and expansion rates might also play an important role in the root architecture responses to inorganic phosphorus deficiency. Overexpression of GmEXB2, which encodes a $\beta$-expansin in soybean, caused an increase of $69 \%$ and $53 \%$ in root cell division and elongation, respectively; $170 \%$ more growth; and $20 \%$ higher inorganic phosphorus uptake at both low and high external phosphorus levels in Arabidopsis Guo et al. (2011).

Therefore, root architecture plays an important role for maximizing phosphorus obtaining because root systems with higher surface area are able to explore a given volume of soil more effectively Lynch, (1995). Some adaptive modifications in root architecture in response to inorganic phosphorus deficiency are well documented in Arabidopsis (Arabidopsis thaliana) and in those species, forming cluster roots Lambers et al., (2006); Osmont et al., (2007); Desnos, (2008); Vance, (2008); Rouached et al., (2010) Fig. (9). 

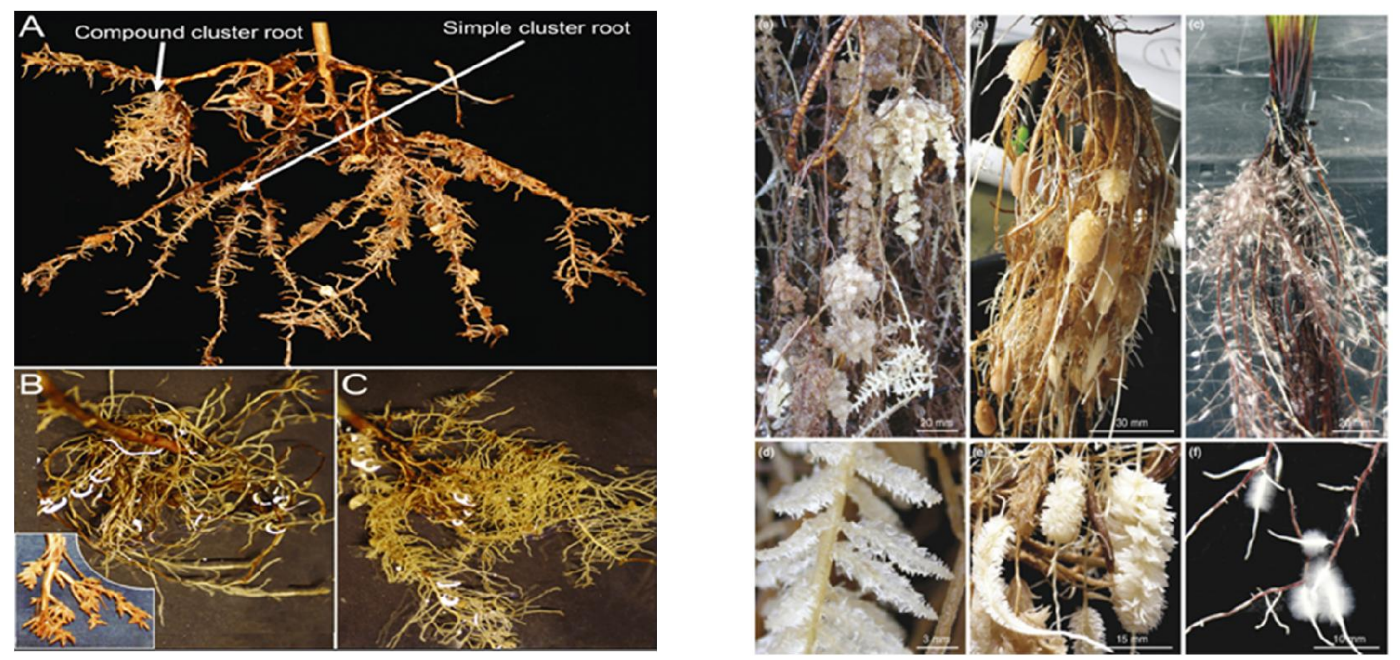

Fig. 9: Illustrates Cluster root (CR) system of seabuckthorn. (A) Simple and compound CR of genotype Pk. (B) Root of cv. BHi10726 grown under low P in sand-vermiculite and (insert) in hydroponics under Fe deficiency. (C) Root of genotype Pk grown under low P in sand-vermiculite.

Adaptive changes of root growth and architecture under phosphorus starvation are related to altered carbohydrate distribution between roots and shoots. These changes caused by plant hormones (Neumann and Römheld, 2002; Nacry et al., 2005), sugar signaling Karthikeyan et al., (2007); Vance, (2010), and nitric oxide in the case of cluster-root formation in white lupin Wang et al., (2010). Root proliferation is stimulated when plant roots encounter nutrient-rich patches, particularly when the patches are rich in phosphorus and /or nitrogen Drew, (1975); Hodge, (2004). The root proliferation in phosphorus rich in top soil layers is related to a decreased root gravitropic response under inorganic phosphorus limitation Bonser et al., (1996), and ethylene may be involved in the regulation of these responses Lynch and Brown, (2008) Fig (10).

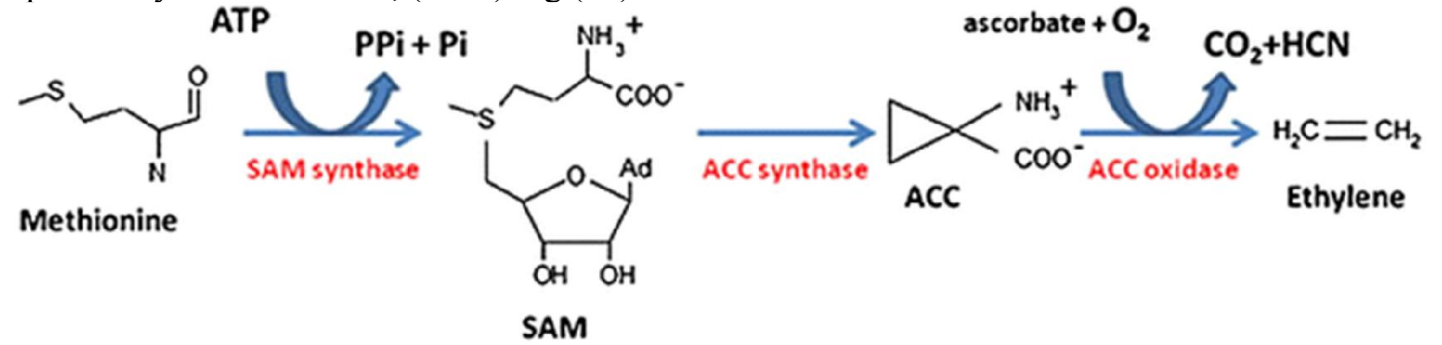

Fig. 10: Represent the key enzymes of ethylene biosynthetic pathway. ACC 1-aminocyclopropane-1carboxylic acid, ATP adenosine triphosphate, $H C N$ hydrogen cyanide, SAM S-adenosylmethionine after Yang and Hoffman(1984)

Root proliferation can be greatly stimulated in the phosphorus enriched soil patches. However, the mechanisms of phosphorus dependent changes in root proliferation in response to local phosphorus supply are not fully understood. Localized application of phosphates plus ammonium significantly enhances $\mathrm{P}$ uptake and crop growth through stimulating root proliferation and rhizosphere acidification in a calcareous soil (Jing et al., 2010).

\section{4-3 Root Exudates}

Root physiology and biochemical responses play an important role for accessing phosphorus from sparingly available pools in soil. Therefore, the exudation of low molecular weight of organic acids (LMWOAAs), proton extrusion, phosphatase exudation and/or association with symbiotic and nonsymbiotic microorganisms present in the rhizosphere are the most important adaptations developed by plants Fig. (8). Availability of inorganic phosphorus and enzymatic activity are strongly affected by soil pH Hinsinger, (2001),(2005) solubility of phosphorus gradually increased by root-induced acidification particularly in alkaline condition of the rhizosphere Gahoonia et al., (1992); Jones and Oburger, (2011). 
Such process occurs mainly due to changes in the acidity of rhizosphere, which influence the mobility and availability of inorganic phosphorus Geelhoed et al., (1999). Plants have the ability to increase or decrease $\mathrm{pH}$ of rhizospheric up to $2-3 \mathrm{pH}$ units, either by absorption or by release of protons in order to equilibrate cation / anion balance Hinsinger et al., (2001). Gahoonia and Nielsen (1996) reported that when $\mathrm{pH}$ of rhizospheric was invariable, the plants (wheat and barley), displayed significant genotypic variation in terms of Phosphorus acquisition efficiency (PAE) indicating that other mechanisms should also be involved in causing variation on phosphorus acquisition. Carboxylates and the corresponding carboxylic acids, also known as $L M W O A A s$, constitute the major fraction of root exudates during phosphorus deficiency Fig. (3). Usually, the most common organic acid anions found in rhizosphere are lactate, acetate, oxalate, succinate, fumarate, malate, citrate, isocitrate, and aconitate Jones, (1998). They have distinct functions on energetic cell metabolism, maintaining charge balance or osmotic potential. It has been widely suggested that $L M W O A A s$ can improve phosphorus availability by mobilizing sparingly available phosphorus forms in the soil solution. This occurs by chelating metals ions like $\mathrm{Al}, \mathrm{Fe}$ or $\mathrm{Ca}$ involved in phosphorus sorption and occupying sorption sites on minerals Jones, (1998). Phosphorus mobilizing activity through LMWOAAs is based on their variable negative charge, which would allow the complexation of metal cations and the displacement of anions from the soil matrix. The above is supported by several studies reporting an increase of organic acids exudation by roots in response to phosphorus deprivation, especially in plants from Proteacea family that possess cluster roots Jones, (1998); Vance et al., (2003); Delgado et al., (2013). In addition, the presence of LMWOAAs in solution has been seen to increased phosphorus availability as compared to water treatments Gerke, (1992); Khademi et al., (2009), (2010). The efficiency for mobilizing phosphorus differs across $L M W O A A s$ as follows: citrate $>$ oxalate $>$ malate $>$ acetate. However, organic acid anioninduced phosphorus release depends on many factors, such as $\mathrm{pH}$, soil mineralogy and anion concentration ( $>100 \mathrm{mM}$ for citrate, $>1 \mathrm{mM}$ for oxalate, malate and tartrate) Bolan et al., (1994); Jones and Darrah, (1994), Lan et al., (1995).

Organic acid have a fast turnover adsorbed in acidic soils and rapidly degraded in alkaline counterparts, with half-lives of several hours Wang et al., (2010). Contrasting evidence found that, despite exuding citrate, pea genotypes were not capable of mobilizing phosphorus from Al-P and Fe-P complexes Pearse et al., (2007). Nevertheless, organic acid production constitutes an important carbon cost in plant metabolism, with $5-25 \%$ of total fixed carbon by photosynthesis being used to sustain exudation. However, this does not seem to significantly affect net biomass production as phosphorus deficiency which can largely reduce growth Johnson et al., (1996); Keerthisinghe et al., (1998). Sparingly available organic P forms represent between $30 \%$ and $90 \%$ of total phosphorus in some soils Borie et al., (1989); Jones and Oburger, (2011). Substantial flows of phosphorus occur between inorganic and organic phosphorus pools in soil through immobilization and mineralization, being both processes mediated predominantly by soil microorganisms Oberson and Joner, (2005); Richardson and Simpson, (2011) Fig (3). In order to utilize source of phosphorus, organic compounds have to be mineralized; that is, organic phosphorus substrates must be hydrolyzed by enzymatic activity of phosphatases to release inorganic phosphorus. This activity seems to be more pronounced in the rhizosphere and it is associated with a depletion of soil organic phosphorus Gahoonia and Nielsen, (1992); Chen et al., (2002); Spohn and Kuzyakov, (2013). Phosphatases are enzymes responsible for catalyzing the hydrolysis of phosphoric acid anhydrides and esters (Schmidt and Laskowski, 1961). The Nomenclature Committee of the International Union of Biochemistry and Molecular Biology classifies these into 5 groups: phosphomonoesterases (EC 3.1.3), phosphodiesterases (EC 3.1.4), triphosphoric monoester hydrolases (EC 3.1.5), enzymes acting on phosphoryl-containing anhydrides (EC 3.6.1) and on $\mathrm{P}-\mathrm{N}$ bonds (EC 3.9) Nannipieri et al., (2011). Phosphomonoesterases are the most abundant enzymes in soils and include acid and alkaline forms and phytases, among others. To date, there is no evidence that any plants produce alkaline phosphomonoesterases. There is an increasing interest on phytases because they hydrolyze inositol phosphates (isomers and lower order derivatives of inositol hexakisphosphate) which generally constitute a major component of soil total organic phosphorus. Ranging from 4 to $40 \%$ of total phosphorus in soils Borie et al., (1989); Smernik and Dougherty, (2007); Turner, (2007), inositol phosphates are readily adsorbed to soil particles and can react with cations ( $\mathrm{Fe}$ and $\mathrm{Al}$ in acidic soils and $\mathrm{Ca}$ in alkaline ones) depending on $\mathrm{pH}$ to form poorly soluble precipitates Shang et al., (1992); Celi and Barberis, (2005). However, in most plant species phytase activity has limited capability to mineralize inositol phosphate due to its low production and exudation from roots and the poor 
availability of the substrate in solution Richardson et al., (2001); George et al., (2007). Attempts to creating transgenic plants overexpressing phytases and /or other phosphatases have been achieved Lung et al., (2005); Wasaki et al., (2009) with little successes under natural soil conditions, where substrate availability is restricted Lung and Lim, (2006); Wang et al., (2009). Interestingly, phosphatase activities are higher near the rhizosphere, with maximum activities found from 2 to $3.1 \mathrm{~mm}$ to the root surface for acid and 1.2 to $1.6 \mathrm{~mm}$ for alkaline phosphomonoesterases, showing a negative correlation with rhizospheric organic phosphorus content in wheat plants Nannipieri et al., (2011). Phosphatase activity is regulated by other factors, such as soil mineralogy, organic matter content, phosphorus availability and bacterial communities present in the rhizosphere Joner and Jakobsen, (1995); Snajdr et al., 2008; Stursova and Baldrian, (2011).

\section{4-4 Microorganisms}

Non-symbiotic soil microorganisms play a key role on organic phosphorus ecosystem dynamics Fig. (3); Harvey et al., (2009); Khan et al., (2010). It has been proposed that all alkaline Phosphomonoesterases found in soil have a microbial origin, mainly bacterial Tabatabai, (1994); Yadav and Tarafdar, (2003). Additionally, free-living bacteria and fungi Unno et al., (2005); Richardson and Simpson, (2011) mediate the majority of inorganic phosphorus (Pi) mineralized from phytase activity. Spohn et al. (2013) using the ${ }^{33} \mathrm{P}$ isotopic approach found that the release of root exudates could be a plant strategy to increase phosphorus mineralization by enhancing microbial activity. Free-living soil microorganisms are believed to be more efficient than plants in absorbing and incorporating Phosphorus into their biomass. Therefore, microbial Phosphorus represents an important soil Sink Xu et al., (2013) and a potential source of available Phosphorus for most plants as microbial Phosphorus is located in more labile intracellular compounds with a fast turnover Oberson and Joner, (2005); Bünemann et alSW., (2013); Hinsinger et al., (2015). Despite having an important role in organic Phosphorus dynamics, most research related to free-living soil microorganisms to enhance PAE (Phosphorus Acquisition Efficiency) has been focused on microorganisms capable of solubilizing sparingly available Phosphorus Wakelin et al., (2004); Leggett et al., (2007). Microorganisms can release protons, LMWOAAs, and other secondary organic metabolites that may contribute to Phosphorus solubilization from minerals Jones and Oburger, (2011). Indeed, between 1-50\% of soil bacteria and about $0.5-0.1 \%$ of soil fungi can be classified as P-solubilizing microorganisms Kucey et al., (1989); Gyaneshwar et al., (2002). Fungal isolates (particularly the Genus Penicillium) stimulate the solubilizing of inorganic phosphorus in both solid and liquid media Gyaneshwar et al., (2002); Leggett et al., (2007); Morales et al., (2011). Groups of bacteria, considers as plant growth promoting rhizobacteria (PGPR), are found in the rhizosphere and have the potential of enhancing PAE mainly through influencing nutrient availability, such as Phosphorus, or indirect through the production of phytohormones, or plant growth regulators as well Richardson et al., (2009). These regulators influence root architecture and other features related to plant development such as auxin, cytokinin, ethylene, gibberellin, and abscisic acid, Peleg and Blumwald, (2011); Vacheron et al., (2013). Although the benefits of using PAE that enhancing microorganisms have been evidenced in laboratory and glasshouse conditions, inconsistent results have been observed in field trials Goos et al., (1994); Karamanos et al., (2010), with the exception of arbuscular mycorrhizal symbiosis established with certain soil fungi.

\section{4-5 Mycorrhizal Association}

Mycorrhizal symbioses can increase the spatial availability of phosphorus, extending the nutrient absorptive surface by formation of mycorrhizal hyphae. Arbuscular mycorrhizal fungi (AMF) form symbiotic associations with the roots of about $74 \%$ of angiosperms Brundrett, (2009) Fig. (11).

In the symbioses, nutrients are transferred by AMF via their extensive mycorrhizal mycelium to plants while in return the fungi receive carbon from the plant. AMF not only influence plant growth through increased uptake of nutrients but also have non-nutritional effects in terms of stabilization of soil aggregates and alleviation of plant stresses caused by biotic and abiotic factors Smith and Read, (2008). 


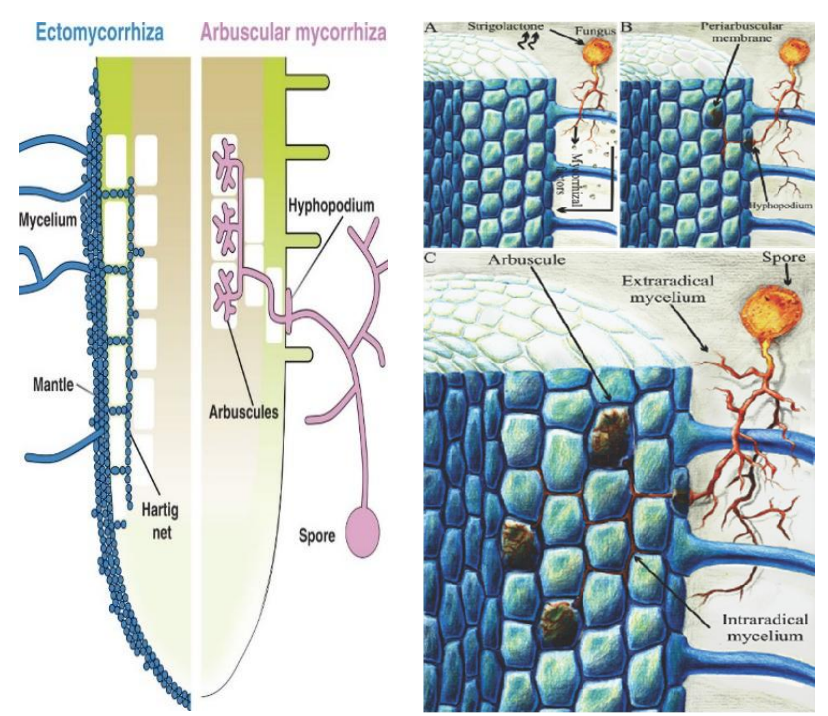

Fig. 11: Represents hypothetical root colonized by an arbuscular mycorrhizal fungus (AMF)

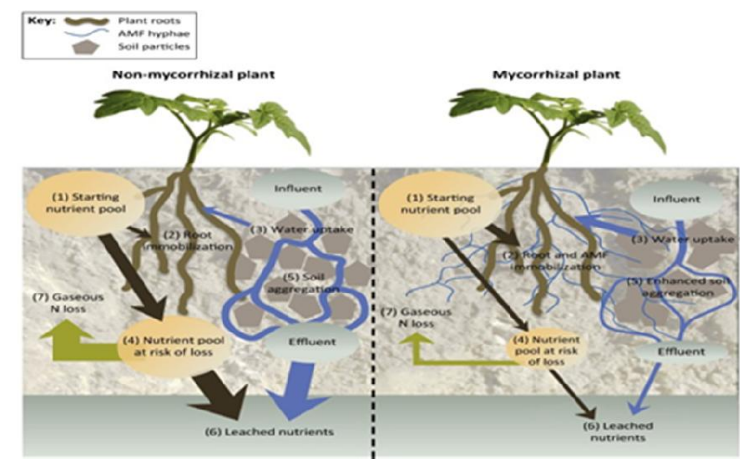

Fig. 12: Illustrates positive effects of arbuscular mycorrhizal (AM) colonization on physical, chemical, biological and nutritional status of soils.

The beneficial effects of AMF and other microorganisms on plant performance and soil health can be very important for the sustainable management of agricultural ecosystems Gianinazzi et al., (2010). A primary benefit of AMF (Arbuscular mycorrhizal fungi) is the improved P uptake conferred on symbiotic plants. In limiting phosphorus soils, mycorrhizal plants usually grow better than nonmycorrhizal plants because of enhanced direct phosphorus uptake of plant roots via the AM pathway. However, plant growth can be suppressed even though the AM pathway contributes greatly to plant phosphorus uptake (Smith and Read, 2008). The growth inhibitions might be cause by the down regulation of the direct root phosphorus uptake pathway Grace et al., (2009). Recent gene expression study Feddermann et al., (2010) shows that plants induce a common set of mycorrhiza induced genes but there is also variability, indicating that there exists functional diversity in AM symbioses. The differential expression of symbiosis-associated genes among different AM associations is related to the fungal species, plant genotypes, and the environmental factors. Therefore, regulation of direct uptake pathways through epidermis and root hairs and AM pathways requires further investigation (Bucher, 2007; Smith et al., 2010).

\section{5- Maximizing phosphorus efficiency in rhizosphere}

Better understanding of phosphorus dynamics in the soil rhizosphere continuously provides an important basis to optimize phosphorus management for improving phosphorus use efficiency for crop production. The effective strategies for phosphorus management may involve a series of multiple- level approaches in association with soil, rhizosphere, and plant processes. phosphorus input into agricultural land can be optimized based on the balance of inputs/outputs of phosphorus Soil-based phosphorus management requires for long-term management strategy to maintain the soil phosphorus available 
supply at an appropriate level through monitoring soil phosphorus fertility, due to the relative stability of phosphorus within soils. Using such approach, the application of phosphorus fertilizer can be reduced by about $20 \%$ as compared to farmer practice for obtaining high yielding cereal crops. This may be of significant importance for saving phosphorus resources without sacrificing crop yields Fig. (13) though it may cause phosphorus accumulation in soil due to high threshold levels and low phosphorus use efficiency by crops.
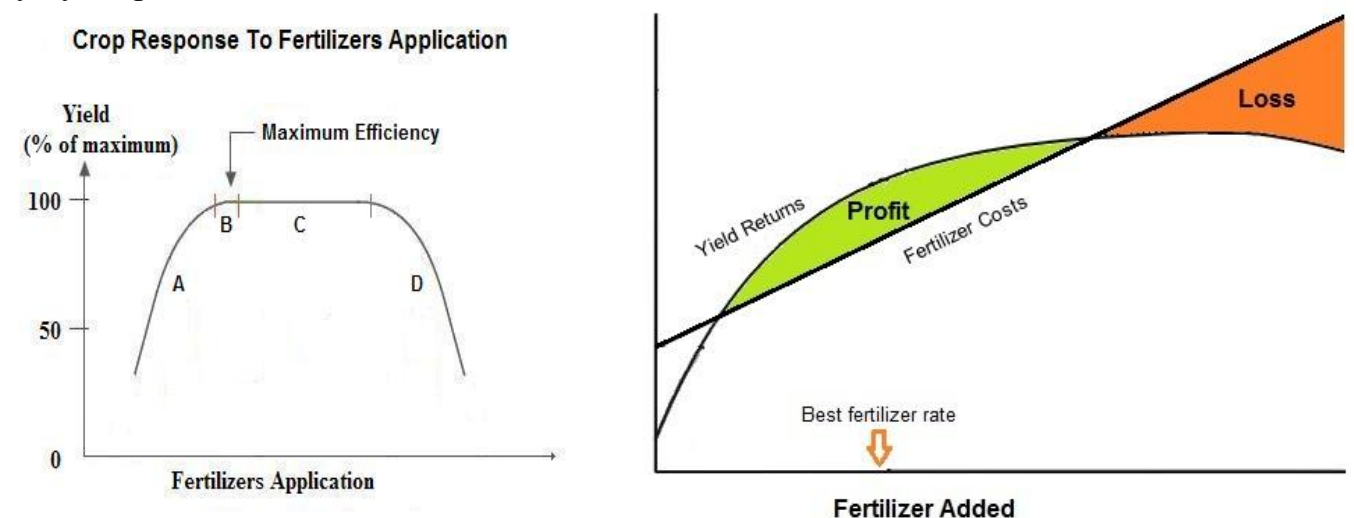

Fig. 13: Illustrates the relation between Fertilizers added and Yield production,

(A)- Yield increases as fertilizer application rate increases

(B)- Yield reaches a maximum.

(C)- Addition of extra fertilizer does not increase the yield

(D) When fertilizer application rates are too high, salinity damages and specific nutrient

, toxicities occur and yield declines

Rhizosphere-based phosphorus management provides an effective approach to improving phosphorus use efficiency and crop yield through exploitation of biological potential for efficient mobilization and acquisition of phosphorus by crops, and reducing the overreliance on application of chemical fertilizer phosphorus. Localized application of phosphorus plus ammonium improved maize (Zea mays) growth by stimulating root proliferation and rhizosphere acidification in a calcareous soil, indicating the potential for field scale modification of rhizosphere processes to improve nutrient use and crop growth Jing et al., (2010). Several researches indicates that faba bean (Vicia faba) can acidify its rhizosphere, whereas maize does not Li et al., (2007). The interaction between intercropping system (bean/maize) may enhanced phosphorus uptake by maze plants. Some soil and rhizosphere microorganisms such as AMF and plant growth promoting rhizobacteria also contribute to plant Phosphorus acquisition Richardson et al., (2009). Field trials of PSM application results in increases in crop yield up to $20 \%$ Jones and Oburger, (2011), and coapplication of AMF and PSM shows synergistic effects in phosphorus acquisition Babana and Antoun, (2006). Alternatively, successful phosphorus management can be achieved by breeding crop cultivars or genotypes more efficient for phosphorus acquisition and use. Great progress has been made in traditional plant breeding programs toward selecting crop varieties for high phosphorus use efficiency. An example of efficient genotype was the wheat (Triticum aestivum) variety Xiaoyan54 that secreted more carboxylates (e.g. malate and citrate) into the rhizosphere than phosphorus inefficient genotypes Li et al., (2005), (2006). Another promising example was soybean (Glycine max) 'BX10' with superior root traits that enable better adaptation to low phosphorus soils Yan et al., (2006). Some important root genetic traits have been identified with potential utility in breeding phosphorus efficient crops, including root exudates, root hair traits, topsoil foraging through basal or adventitious rooting Gahoonia and Nielsen, (2004); Lynch and Brown, (2008). The ability to use insoluble phosphorus compounds in soils can be enhanced by engineering crops to exude more phytase, which results from overexpression of a fungal phytase gene George et al., (2005b). The integration of genetically improved phosphorus efficient crops with advanced phosphorus management in the soil plant system is important for improving nutrient use efficiency and sustainable crop production. Cooperative work always requires between scientists from different disciplines in the crop, plant, and soil sciences. Issues involving phosphorus use in agriculture are becoming important in various fields beyond agronomy. Phosphorus management involves a series of strategies such as 
increasing phosphorus uptake efficiency by plant and animal, reducing overuse of chemical fertilizer phosphorus and improving recycling efficiency of manure phosphorus. It is estimated that animal manure may substitute for $1.46 \mathrm{Mt}$ phosphorus of chemical phosphorus fertilizers, and recycling manure is thus of an importance for optimizing phosphorus resource use in the future

\section{6- Conclusion}

Phosphorus fertilization is predominantly controlled by Phosphorus dynamics in the soil - plant relationships. The distribution and dynamics of Phosphorus in soil has a significant due to the variation of climatic conditions. Root distribution (Root architecture) throughout the soil-rhizosphere where the presence of Phosphorus fertilizer are located, plays an important part for phosphorus utilization efficiency. Moreover, root network can enhance the phosphorus mobilization particularly in the soil rhizosphere through root excretions such as carboxylates, protons, and phosphatases. The interaction between the adaptation of root morphology and physiology to low adequate of phosphorus might effectively match heterogeneous Phosphorus supply and distribution in soil. This phenomenon enhancing the bioavailability of Phosphorus in soil. Such integration of Phosphorus dynamics from soil to plant through the soil rhizosphere gradually provides a comprehensive state of available Phosphorus behavior and efficient acquisition in association with adaptation of plant approaches.

Significant progress has been made for understanding soil, rhizosphere, and plant processes associated with soil Phosphorus transformation, mobilization , acquisition, and deficiency responses, many aspects of overall Phosphorus dynamics in the soil / rhizosphere-plant are not thoroughly understood, including regulation of Phosphorus acquisition and Phosphorus starvation rescue mechanisms in plants, the complex coordination of root morphology, physiological and biochemical responses under varying Phosphorus availability, and plant sensing of heterogeneous Phosphorus supply in soil. Given the importance of Phosphorus to plants and its importance as a strategic resource, a better understanding of Phosphorus dynamics in the soil / rhizosphere plant is necessary to guide establishment of integrated Phosphorus management strategies involving manipulation of soil and rhizosphere processes, development of Phosphorus efficient crops, and improving Phosphorus recycling efficiency in the future.

\section{References}

Ai, P., S. Sun, J. Zhao, X. Fan, W. Xin, Q. Guo, L. Yu, Q. Shen, P. Wu, A.J. Miller et al, 2009. Two rice phosphate transporters, OsPht1; 2 and OsPht1; 6, have different functions and kinetic properties in uptake and translocation. Plant, J. 57: 798-809.

ANDA: Associaço Nacional para difuso de Adubos, 2016. Principais indicadores do setor de fertilizantes. http://anda.org.br/index .phpmpg=03.00.00. Accessed 21 Dec 2018.

Arai, Y., and D.L. Sparks, 2007. Phosphate reaction dynamics in soils and soil minerals: a multiscale approach. Adv .Agron. 94: 135-179.

Babana, A.H., and H. Antoun, 2006. Effect of Tilemsi phosphate rock-solubilizing microorganism on phosphorus uptake and yield of field-grown wheat (Triticum aestivum L.) in Mali. Plant Soil 287: $51-58$

Benbi, D.K. and R.J. Gilkes, 1987. The movement into soil of P from superphosphate grains and its available to plants. Fert .Res. 12: 21-36.

Bieleski, R.L., 1973. Phosphate pools, phosphate transport, and phosphate availability. Annu. Rev. Plant Physiol. 24: 225-252.

Bolan, N.S., R. Naidu, S. Mahimairaja, and S. Baskaran. 1994. Influence Of low-molecular-weight organic acids on the solubilization of Phosphates. Biol. Fert. Soils 18, 311-319.

Bonser, A.M., J. Lynch, and S. Snapp, 1996. Effect of phosphorus deficiency on growth angle of basal roots in Phaseolus vulgaris. New Phytol., 132: 281-288.

Borie, F., H. Zunino, and L. Martinez, 1989. Macromolecule-p associations and Inositol phosphates in some Chilean volcanic soils of temperate regions. Commun. Soil Sci. Plant Anal. 20, 1881-1894. Doi: 10.1080/00103628909368190.

Bucher, M., 2007. Functional biology of plant phosphate uptake at root and mycorrhiza interfaces. New Phytol 173: 11-26. 
Bünemann, E. K., B. Keller, D. Hoop, K. Jud, P. Boivin, and E. Frossard, 2013. Increased availability of phosphorus after drying and rewetting Of a grassland soil: processes and plant use. Plant Soil 370, 511-526. Doi: 10.1007/s11104-013-1651-y.

Carvajal-Mu oz, J.S., and C.E. Carmona-Garcia, 2012. Benefits and limitations of bio fertilization in agricultural practices. Livestock Res. Rural Develop 24:1-8.

Celi, L., and E. Barberis, 2005. "Abiotic stabilization of organic phosphorus in the Environment," in Organic Phosphorus in the Environment, eds B. L. Turner, E. Frossard, and D. Baldwin (Wallingford: CABI Publishing) 113-132.

Chiou, T.J., and S.I. Lin 2011. Signaling network in sensing phosphate availability in plants. Annu. Rev. Plant Biol. 62:185-206.

Chiou, T.J., H. Liu, and M.J. Harrison, 2001. The spatial expression patterns of a phosphate transporter $(\mathrm{MtPT1})$ from Medicago truncatula indicate a role in phosphate transport at the root/soil interface. Plant J. 25:1-15.

Condron, L.M., B.L. Turner, and B.J. Cade-Menun, 2005. Chemistry and dynamics of soil organic phosphorus. In JT Sims, AN Sharpley, eds, Phosphorus: Agriculture and the Environment. American Society of Agronomy, Crop Science Society of America, Soil Science Society of America, Inc., Madison, WI, 87-121.

Cordell, D., J.O. Drangert, and S. White, 2009. The story of phosphorus: global food security and food for thought. Glob Environ Change 19: 292-305.

Cubero, B., Y. Nakagawa, X. Jiang, K. Miura, F. Li, et al., 2009. The phosphate transporter PHT4;6 is a determinant of salt tolerance that is localized to the Golgi apparatus of Arabidopsis. Mol. Plant 2:535-52.

Davies, T., J. Ying, Q. Xu, Z. Li, J. Li, and R. Gordon-Weeks, 2002. Expression analysis of putative high-affinity phosphate transporters in Chinese winter wheats. Plant Cell Environ. 25:1325-40.

Delgado, M., A. Zúñiga-Feest, M.Alvear, and F. Borie, 2013. The Effect of phosphorus on cluster-root formation and functioning Embothrium coccineum (R. et J. Forst.) Plant Soil 373, 765-773. Doi: 10.1007/s11104-013-1829-3.

Desnos, T., 2008. Root branching responses to phosphate and nitrate. Curr Opin Plant Biol 11: 82-87.

Devau, N., E. Le Cadre, P. Hinsinger, and F. Ge'rard, 2010. A mechanistic model for understanding root-induced chemical changes controlling phosphorus availability. Ann Bot (Lond) 105: 11831197.

Dou, Z., J.D. Toth, D.T. Galligan, C.F. Ramberg, and J.D. Ferguson, 2000. Laboratory procedures for characterizing manure phosphorus. J Environ Qual 29:508-514.

Drew, M.C., 1975. Comparison of the effects of a localized supply of phosphate, nitrate, ammonium and potassium on the growth of the seminal root system, and the shoot, in barley. New Phytol 75: 479-490.

Fan, C., X. Wang, R. Hu, Y. Wang, C. Xiao, et al. 2013. The pattern of Phosphate transporter 1 genes evolutionary divergence in Glycine max L. BMC Plant Biol. 3:48.

Feddermann, N., R. Finlay, T. Boller, and M. Elfstrand, 2010. Functional diversity in arbuscular mycorrhizal - the role of gene expression, phosphorus nutrition and symbiotic efficiency. Fungal Ecol 3: 1-8.

Gahoonia, T.S., and N.E. Nielsen, 2003. Phosphorus (P) uptake and growth of a root hairless barley mutant (bald root barley, brb) and wild type in low- and high-P soils. Plant Cell Environ. 26:1759-66

Gahoonia, T. S., and N. E. Nielsen, 1996. Variation in acquisition of soil Phosphorus among wheat and barley genotypes. Plant Soil 178, 223-230. Doi: 10.1007/BF00011587.

Gahoonia, T. S., N. Claassen, and A. Jungk, 1992. Mobilization of phosphate in different soils by ryegrass supplied with ammonium or nitrate. Plant Soil 140,241-248. doi: 10.1007/BF00010600

Gahoonia, T.S., G. Care, and N.E. Nielsen, 1997. Root hairs and phosphorus Acquisition of wheat and barley cultivars. PlantSoil 191, 181-188.doi:10.1023/A:1004270201418.

Geelhoed, J. S., W. H. van Riemsdijk, and G. R. Findenegg, 1999. Simulation of the effect of citrate exudation from roots on the plan Availability of phosphate adsorbed on goethite. Eur. J. Soil Sci. 50, 379-390. Doi: 10.1046/j.1365-2389.1999.00251.x. 
George, T.S., R.J .Simpson, P.A. Hadobas, and A.E. Richardson, 2005b. Expression of a fungal phytase gene in Nicotiana tabacum improves phosphorus nutrition of plants grown in amended soils. Plant Biotechnol J. 3: 129-140.

George, T.S., P.J. Gregory, R.J. Simpson, and A.E. Richardson, 2007. Differential interactions of Aspergillus niger and Peniophora lycii phytases with Soil particles affects the hydrolysis of inositol phosphates. Soil Biol. Biochem. 39,793-803. Doi: 10.1016/j.soilbio.2006.09.029.

Gerke, J., 1992.Phosphate, aluminium and iron in the soil solution of three different soils In relation to varying concentrations of citric acid, Z. Pflanznahr. Bodenkd.155: 339-343.

Gianinazzi, S., A. Gollotte, M.N. Binet, D. van Tuinen, D. Redecker, and D. Wipf, 2010. Agroecology: the key role of arbuscular mycorrhizas in ecosystem services. Mycorrhiza 20: 519-530.

Gilbert, N., 2009. Environment: the disappearing nutrient. Nature 461: 716-718.

Glassop, D., R.M. Godwin, S.E. Smith, and F.W. Smith 2007. Rice phosphate transporters associated withnphosphate uptake in rice roots colonised with arbuscular mycorrhizal fungi. Can. J. Bot. 85:644-51.

Goff, S.A., D. Ricke, T.H. Lan, G. Presting, R. Wang, et al. 2002. A draft sequence of the rice genome (Oryza sativa L. ssp. japonica. Science, 296:92-100.

Goos, R. J., B. E. Johnson, and R. W. Stack, 1994. Penicillium bilaji And phosphorus fertilization effects on the growth, development yield And common root rot severity of spring wheat. Fert. Res. 39, 97-103. Doi: 10.1007/BF00750908.

Grace, E.J., F.A. Smith, and S.E. Smith, 2009. Deciphering the arbuscular mycorrhizal pathway of P uptake in non-responsive plant species. InCAzco' n- Aguilar, JM Barea, S Gianinazzi, eds, Mycorrhizas-Functional Processes and Ecological Impact. Springer, Berlin, 1-18.

Grace, E. J., O. Cotsaftis, M.Tester, F. A. Smith, and S. E. Smith, 2009. Arbuscular mycorrhizal inhibition of growth in barley cannot be Attributed to extent of colonization, fungal phosphorus uptake or effects on Expression of plant phosphate transporter genes. New Phytol. 181, 938-949. Doi: 10.1111/j.1469-8137.2008.02720.x.

Guo, B., Y. Jin, C. Wussler, E. Blancaflor, C. Motes, and W. Versaw, 2008. Functional analysis of the Arabidopsis PHT4 family of intracellular phosphate transporters. New Phytol. 177:889-98.

Guo, W., J. Zhao, X. Li, X. Yan, and H. Liao, 2011. A soybean $\beta$-expansin gene GmEXPB2 intrinsically involved in root system architecture responses to abiotic stresses. Plant J. 66:541-52.

Gyaneshwar, P., G. Naresh Kumar, L. J. Parekh, and P. S. Poole, 2002. Role of Soil microorganisms in improving P nutrition of plants. Plant Soil 245, 83-93. Doi: 10.1023/A: 1020663916259.

Ha, S., and L.S. Tran, 2014. Understanding plant responses to phosphorus starvation for improvement of plant tolerance to phosphorus deficiency by biotechnological approaches. Crit. Rev. Biotechnol. 34:16-30.

Hansen, J.C., B.J. Cade-Menun, and D.G. Strawn, 2004. Phosphorus speciation in manure-amended alkaline soils. J Environ Qual 33: 1521-1527.

Hariadi, Y.C., A.Y. Nurhayati, and P. Hariyani, 2016. Biophysical Monitoring on the Effect on Different Composition of Goat and Cow Manure on the Growth Response of Maize to Support Sustainability. Agric Ecosyst 9:118-127.

Harrison, A.F., 1987. Soil Organic Phosphorus-A Review of World Literature.

Harrison, M.J., G.R. Dewbre, and J. Liu, 2002. A phosphate transporter from Medicago truncatula involved in the acquisition of phosphate released by arbuscular mycorrhizal fungi. Plant Cell 14:2413-29

Harvey, P. R., R. A. Warren, and S. A. Wakelin, 2009. Potential to improve Root access to phosphorus: the role of non-symbiotic microbial inoculants in The rhizosphere. Crop Pasture Sci. 60, 144151. Doi: 10.1071/CP08084.

Hinsinger, P., 2001. Bioavailability of soil inorganic P in the rhizosphere as affected by root-induced chemical changes: a review. Plant Soil 237: 173-195.

Hinsinger, P., A.G. Bengough, D. Vetterlein, and I.M. Young, 2009. Rhizosphere: biophysics, biogeochemistry, and ecological relevance. Plant Soil 321:117-152.

Hinsinger, P., G.R. Gobran, P.J. Gregory, and W.W. Wenzel, 2005. Rhizosphere geometry and heterogeneity arising from root-mediated physical and chemical processes. New Phytol 168: 293303. 
Hinsinger, P., L. Herrmann, A. R. Lesueur, A. Robin, J. Trap, K. Waithaisong, et al., 2015. Impact of roots, microorganisms and micro fauna on the Fate of soil phosphorus in the rhizosphere. Annu. Plant Rev. 48, 77-408. Doi: 10.1002/9781118958841.ch13.

Hodge, A., 2004. The plastic plant: root responses to heterogeneous supplies of nutrients. New Phytol 162: 9-24.

Jing, J.Y., Y.K. Rui, F.S. Zhang, Z. Rengel, and J.B. Shen, 2010. Localized application of phosphorus and ammonium improves growth of maize seedlings by stimulating root proliferation and rhizosphere acidification. Field Crops Res 119: 355-364.

Johnson, J. F., D. L. Allan, C. P. Vance, and G. Weiblen, 1996. Root Carbon dioxide fixation by phosphorus-deficient Lupinus albus: contribution To organic-acid exudation by proteoid roots. Plant Physiol. 112, 19-30. Doi:10.1104/pp.112.1.19.

Jones, D.L., and E. Oburger, 2011.Solubilization of phosphorus by soil microorganism. In EK Buenemann, A Oberson, E Frossard, eds, Phosphorus in Action. Springer, New York, pp 169198

Jones, D. L., 1998. Organic acids in the rhizosphere-a critical review. Plant Soil 205, 25-44. Doi: 10.1023/A:1004356007312.

Jones, D. L., and E. Oburger, 2011. "Solubilization of phosphorus by soil Microorganisms," in Phosphorus in Action. Biological Processes in Soil Phosphorus Cycling, Eds E. K. Bünemann, A. Oberson, and E. Frossard (Berlin; Heidelberg: Springer-Verlag), 169-198.

Jones, D. L., and E. Oburger, 2011. "Solubilization of phosphorus by soil Microorganisms," in Phosphorus in Action. Biological Processes in Soil Phosphorus Cycling, Eds E. K. Bünemann, A. Oberson, and E. Frossard (Berlin; Heidelberg: Springer-Verlag), 169-198.

Jones, L.J., and P.R., DARRAH, 1994. Role of root derived organic acids in the mobilization Of nutrients in the rhizosphere, Plant Soil, 166: 247-257.

Karamanos, R. E., N. A. Flore, and J. T. Harapiak, 2010. Re-visiting use of Penicillium bilaii with phosphorus fertilization of hard red spring wheat. Can. J. Plant Sci. 90, 265-277. Doi: 10.4141/CJPS09123.

Karthikeyan, A., D. Varadarajan, A. Jain, M. Held, N. Carpita, and K. Raghothama, 2007. Phosphate starvation responses are mediated by sugar signaling in Arabidopsis. Planta 225:907-18.

Keerthisinghe, G., et al., 1998. Effect of phosphorus supply on the formation and function of proteoid roots of white lupin \{Lupinus albus L.), Plant Cell Environ. 21: 467-478.

Keerthisinghe, G., P. J. Hocking, P. R. Ryan, and E. Delhaize, 1998. Effect of phosphorus supply on the formation and function of proteoid Roots of white lupin (Lupinus albus L. Plant Cell Environ. 21, 467-478. Doi: 10.1046/j.1365-3040.1998.00300.x.

Khademi, Z., D. L. Jones, M. J. Malakouti, and F. Asadi, 2010. Organic Acids differ in enhancing phosphorus uptake by Triticum aestivum L. Effects of rhizosphere concentration and counter ion. Plant Soil 334, 151-159. Doi: 10.1007/s11104-009-0215-7.

Khademi, Z., D. L. Jones, M. J. Malakouti, F. Asadi, and M. Ardebili, 2009. Organic acid mediated nutrient extraction efficiency in three calcareous soil Aust. J. Soil Res. 47, 213-220. Doi: 10.1071/SR07179

Khan, M. S., A. Zaidi, M. Ahemad, M. Oves, and P. A. Wani, 2010. Plant growth Promotion by phosphate solubilizing fungi-current perspective. Arch. Agron. Soil Sci. 56, 73-98. Doi: $10.1080 / 03650340902806469$.

Kucey, R. M. N., H. H. Jenzen, and M. E. Leggett, 1989. Microbially Mediated increases in plant available phosphorus. Adv. Agron. 42, 199-228. Doi: 10.1016/S0065-2113(08)60525-8.

L' opez-Bucio, J., A. Cruz-Ram'1rez, and L. Herrera-Estrella, 2003. The role of nutrient availability in regulating root architecture. Curr. Opin. Plant Biol. 6:280-87.

L' opez-Bucio, J, E. Hern'andez-Abreu, L. S'anchez-Calder 'on, M.F. Nieto-Jacobo, J. Simpson, and L. Herrera- Estrella, 2002. Phosphate availability alters architecture and causes changes in hormone sensitivity in the Arabidopsis root system. Plant Physiol. 129:244-56.

L' opez-Bucio, J., E. Hern'andez-Abreu, L. S'anchez-Calder 'on, A. P'erez-Torres, R.A. Rampey, et al., 2005. An auxin transport independent pathway is involved in phosphate stress-induced root architectural alterations in Arabidopsis. Identification of BIG as a mediator of auxin in pericycle cell activation. Plant Physiol. 137:681-91. 
Lambers, H., M.W. Shane, M.D. Cramer, S.J. Pearse, and E.J. Veneklaas, 2006. Root structure and functioning for efficient acquisition of phosphorus: matching morphological and physiological traits. Ann Bot (Lond) 98:693-713.

Lan, M., N. B. Comerford, and T. R. Fox, 1995. Organic anions effect on Phosphorus release from spodic horizons. Soil Sci. Soc. Am. J. 59, 1745-1749. Doi:10.2136/sssaj1995.03615995005900060034x

Larsen, S., 1967. Soil phosphorus. Adv Agron 19: 151-210 Li J, Liu X, Zhou W, Sun J, Tong Y, Liu W, Li ZS, Wang P, Yao S, 1995. Technique of wheat breeding for efficiently utilizing soil nutrient elements. Sci China Ser B 38: 1313-1320.

Leggett, M., J. Cross, G. Hnatowich, and G. Holloway, 2007. "Challenges In commercializing a phosphate-solubilizing microorganisms: Penicillium Bilaiae, a case history," in First International Meeting on Microbial Phosphate Solubilization, Eds E. Velázquez, C. Rodríguez-Barrueco, E. Velázquez, and C. Rodríguez-Barrueco (Dordrecht: Springer), 215-222.

Li, L., S.M., Li, J.H. Sun, L.L. Zhou, X.G. Bao, H.G. Zhang, and F.S. Zhang, 2007. Diversity enhances agricultural productivity via rhizosphere phosphorus facilitation on phosphorus-deficient soils. Proc .Natl. Acad .Sci. USA 104: 11192-11196.

Li, H. Y., Y. G. Zhu, P. Marschner, F. A. Smith, and S. E. Smith, 2005. Wheat Responses to arbuscular mycorrhizal fungi in a highly calcareous soil differ from Those of clover, and change with plant development and P supply. Plant Soil 277, 221-232. Doi: 10.1007/s11104-005-7082-7.

Li, H., S. E. Smith, R. E. Holloway, Y. Zhu, and F. A. Smith, 2006. Arbuscular Mycorrhizal fungi contribute to phosphorus uptake by wheat grown in a Phosphorus-fixing soil even in the absence of positive growth responses. New Phytol. 172, 536-543. Doi: 10.1111/j.14698137.2006.01846.x.

Lindsay, W.L., A.W. Frazier, and H.F. Stephenson, 1962. Identification of reaction products from phosphate fertilizers in soils. Soil Sci Soc Proc 26: 446-452.

Liu, J., W.K. Versaw, N. Pumplin, S.K. Gomez, L.A. Blaylock, and M.J. Harrison, 2008. Closely related members of the Medicago truncatula PHT1 phosphate transporter gene family encode phosphate transporters with distinct biochemical activities. J. Biol. Chem. 283:24673-81.

Luengo, C., M. Brigante, J. Antelo, and M. Avena, 2006. Kinetics of phosphate adsorption on goethite: comparing batch adsorption and ATR-IR measurements. J Colloid Interface Sci 300: 511-518.

Lung, S.-C., and B. L. Lim, 2006. Assimilation of phytate-phosphorus by the extracellular phytase activity of tobacco (Nicotiana tabaccum) is Affected by the availability of soluble phytate. Plant Soil 279, 187-199. Doi: 10.1007/s11104-005-1009-1.

Lung, S.-C., W.-L. Chan, W. Yip, L. Wang, E. C. Yeung, and B. L. Lim, 2005. Secretion of betapropeller phytase from tobacco and Arabidopsis roots enhances phosphorus utilization. Plant Sci. 169, 341-349. Doi: 10.1016/j.plantsci.2005.03.00.

Lynch, J.P., 1995. Root architecture and plant productivity. Plant Physiol. 109:7-13.

Lynch, J.P., and K.M. Brown, 2008. Root strategies for phosphorus acquisition. In $\backslash$ PJ White, JP Hammond, eds, The Ecophysiology of Plant-Phosphorus Interactions. Springer, Dordrecht, The Netherlands, 83-116.

Marschner, H., 1995. Mineral Nutrition of Higher Plants, Ed 2. Academic Press, London, p 889

Martins, M.A., C. Santos, M.M. Almeida, and M.E.V. Costa, 2008. Hydroxyapatite micro- and nanoparticles: nucleation and growth mechanisms in the presence of citrate species. J. Colloid Interface Sci. 318: 210-216.

Min, J., H. Zhang, and W. Shi, 2012. Optimizing nitrogen input to reduce nitrate leaching loss in greenhouse vegetable production. Agric. Water Manag., 111:53-59.

Moody, P.W., D.G. Edwards, and L.C. Bell, 1995. Effect of banded fertilizers on soil solution composition and short-term root growth: II. Monocalcium phosphate with and without gypsum. Aust. J. Soil Res., 33: 899-914.

Morales, A., M. Alvear, E. Valenzuela, C. E. Castillo, and F. Borie, 2011. Screening, evaluation and selection of phosphate-solubilizing Fungi as potential biofertilisers. J. Soil Sci. Plant Nut. 11, 89103. Doi: $10.4067 /$ S0718-95162011000400007.

Mudge, S.R., A.L. Rae, E. Diatloff, and F.W. Smith 2002. Expression analysis suggests novel roles for members of the Pht1 family of phosphate transporters in Arabidopsis. Plant J.31:341-53. 
Muraishi, C.T., M.C. Alves, A. da Silva Jonior, and Z.M. de Souza, 2011. Chemical attributes of a savannah Typic Hapludox soil under management systems. Acta .Sci. Agron. 33:551-557.

Nacry, P., G. Canivenc, B. Muller, A. Azmi, H. Van Onckelen, M. Rossignol, and P. Doumas, 2005. A role for auxin redistribution in the responses of the root system architecture to phosphate starvation in Arabidopsis. Plant Physiol. 138: 2061-2074.

Nagy, R., V. Karandashov, V. Chague, K. Kalinkevich, M.B. Tamasloukht, et al. 2005. The characterization of novel mycorrhiza-specific phosphate transporters from Lycopersicon esculentum and Solanum tuberosum uncovers functional redundancy in symbiotic phosphate transport in solanaceous species. Plant $J .42: 236-50$.

Nagy, R., M.J.V. Vasconcelos, S. Zhao, J. McElver, W. Bruce, et al. 2006. Differential regulation of five Pht1 phosphate transporters from maize (Zea mays L.) Plant Biol. 8:186-97.

Nannipieri, P., L. Giagnoni, L.Landi, and G. Renella, 2011. "Role of phosphatase Enzymes in soil," in Phosphorus in Action. Biological Processes in Soil Phosphorus Cycling, Eds E. K. Bünemann, A. Oberson, and E. Frossard (Berlin; Heidelberg: Springer-Verlag), 169-198.

Nannipieri, P., L.Giagnoni, L. Landi, and G. Renella, 2011. "Role of phosphatase Enzymes in soil," in Phosphorus in Action. Biological Processes in Soil Phosphorus Cycling, Eds E. K. Bünemann, A. Oberson, and E. Frossard (Berlin; Heidelberg: Springer-Verlag), 169-198.

Neumann, G., A. Massonneau, E. Martinoia, and V. Ro"mheld, 1999. Physiological adaptations to phosphorus deficiency during proteoid root development in white lupin. Planta., 208: 373-382.

Neumann, G., and V. Ro"mheld, 2002. Root-induced changes in the availability of nutrients in the rhizosphere. In Y Waisel, A Eshel, U Kafkafi, eds, Plant Roots, The Hidden Half, Ed 3. Marcel Dekker, Inc., New York, 617-649.

Oberson, A., and E. J. Joner, 2005. "Microbial turnover of phosphorus in soil," in Organic Phosphorus in the Environment, Eds B. L. Turner, E. Frossard, and D.S. Baldwin (Wallingford: CABI), 133164.

Oberson, A., and E. J. Joner, 2005. "Microbial turnover of phosphorus in soil," in Organic Phosphorus in the Environment, Eds B. L. Turner, E. Frossard, and D. S. Baldwin (Wallingford: CABI), 133164.

Oelkers, E.H., and E. Valsami-Jones, 2008. Phosphate mineral reactivity and global sustainability. Elements 4: 83-87.

Osmont, K.S., R. Sibout, and C.S. Hardtke, 2007. Hidden branches: developments in root system architecture. Annu. Rev. Plant Biol. 58: 93-113.

P'erez-Torres, C.-A., J. L' opez-Bucio, A. Cruz-Ram'ırez, E. Ibarra-Laclette, and S. Dharmasiri, 2008. Phosphate availability alters lateral root development in Arabidopsis by modulating auxin sensitivity via a mechanism involving the TIR1 auxin receptor. Plant Cell 20:3258-72.

Parfitt, R.L., 1989. Phosphate reactions with natural allophone, ferrihydrite and goethite. J. Soil Sci., 40: 359-369.

Paszkowski, U., S. Kroken, C. Roux, and S.P. Briggs, 2002. Rice phosphate transporters include an evolutionarily divergent gene specifically activated in arbuscular mycorrhizal symbiosis. Proc. Natl. Acad. Sci. USA 99:13324-29.

Pearse, S. J., E. J. Veneklaas, G. Cawthray, M. D. Bolland, and H. Lambers, 2007. Carboxylate composition of root exudates does not relate consistently to a crop Species' ability to use phosphorus from aluminium, iron or calcium phosphate Sources. New Phytol. 173,181-190. Doi: 10.1111/j.1469-8137.2006.01897.x.

Peleg, Z., and E. Blumwald, 2011. Hormone balance and abiotic Stress tolerance in crop plants. Curr. Opin. Plant Biol. 14, 290-295. Doi: 10.1016/j.pbi.2011.02.001.

Pierzynski, G.M., R.W. McDowell, and J.T. Sims, 2005. Chemistry, cycling, and potential moment of inorganic phosphorus in soils. In JT Sims, AN Sharpley, eds, Phosphorus: Agriculture and the Environment. American Society of Agronomy, Crop Science Society of America, Soil Science Society of America, Inc., Madison, WI, 53-86.

Pinto, F.A., F.L. Santos, F.D. Terra, D.O. Ribeiro, R.R.J. Sousa, E.D. Souza, M.A.C. Carneiro, and H.P. Paulino, 2012. Atributos de solo sob pastejo rotacionado em funçৎo da aplicaçəo de cama de peru. Pesq Agropec Trop. 42:254-262. 
Qin, L., Y. Guo, L. Chen, R. Liang, M. Gu, et al., 2012. Functional characterization of 14 Pht1 family genes in yeast and their expressions in response to nutrient starvation in soybean. PLoS ONE 7:e47726.

Qin, L., J. Zhao, J. Tian, L. Chen, Z. Sun, et al. 2012. The high-affinity phosphate transporter GmPT5 regulates phosphate transport to nodules and nodulation in soybean. Plant Physiol. 159:1634-43

Rae, A.L., D.H. Cybinski, J.M. Jarmey, and F.W. Smith 2003. Characterization of two phosphate transporters from barley: evidence for diverse function and kinetic properties among members of the Pht1 family. Plant Mol. Biol. 53:27-36.

Raghothama, K.G., 1999. Phosphate acquisition. Annu Rev Plant Physiol Plant Mol Biol 50: 665-693

Raghothama, K.G., and A.S. Karthikeyan, 2005. Phosphate acquisition. Plant Soil 274:37-49.

Ramos, B.Z., J.P.V.F. Toledo, J.M. Lima, M.E. Serafim, A.R.R. Bastos, P.T.G. Guimares, and A.R. Coscione, 2013. Doses de gesso em cafeeiro: influência nos teores de clcio, magnésio, potssio e pH na soluço de um latossolo vermelho distrifico. Rev Bras Cienc Solo 37:1018-1026.

Richardson, A.E., J.M. Barea, A.M. McNeill, and C. Prigent-Combaret, 2009. Acquisition of phosphorus and nitrogen in the rhizosphere and plant growth promotion by microorganism. Plant Soil 321: 305-339.

Richardson, A. E., and R. J. Simpson, 2011. Soil microorganisms Mediating phosphorus availability. Plant Physiol. 156, 989-996. Doi: 10.1104/pp.111.175448.

Richardson, A. E., and R. J. Simpson, 2011. Soil microorganisms Mediating phosphorus availability. Plant Physiol. 156, 989-996. Doi: 10.1104/pp.111.175448.

Richardson, A. E., J. M. Barea, A. M. McNeill, and C. Prigent-Combaret, 2009. Acquisition of phosphorus and nitrogen in the rhizosphere and Plant growth promotion by microorganisms. Plant Soil, 321, 305-339. Doi: 10.1007/s11104-009-9895-2.

Richardson, A. E., P. A.Hadobas, and J. E. Hayes, 2001. Extracellular Secretion of Aspergillus phytase from Arabidopsis roots enables plants to obtain Phosphorus from phytate. Plant J. 25, 641-649. Doi: 10.1046/j.1365-313x.2001.00998.x.

Rouached, H., A.B. Arpat, and Y. Poirier, 2010. Regulation of phosphate starvation responses in plants: signaling players and cross-talks. Mol Plant 3:288-299.

S'anchez-Calder 'on, L., J. L' opez-Bucio, A. Chac'on-L' opez, A. Cruz-Ram'1rez, F. Nieto-Jacobo, et al. 2006. Phosphate starvation induces a determinate developmental program in the roots of Arabidopsis thaliana. Plant Cell Physiol., 46:174-84.

S'anchez-Calder 'on, L., J. L' opez-Bucio, A. Chac'on-L' opez, A. Guti'errez-Ortega, E. Hern'andezAbreu, and L. Herrera-Estrella, 2005. Characterization of low phosphorus insensitive mutants reveals a crosstalk between low phosphorus-induced determinate root development and the activation of genes involved in the adaptation of Arabidopsis to phosphorus deficiency. Plant Physiol. 140:879-89.

Sch unmann, P.H.D., A.E. Richardson, F.W. Smith, and E. Delhaize, 2004. Characterization of promoter expression patterns derived from the Pht1 phosphate transporter genes of barley (Hordeum vulgare L. J. Exp. Bot. 55:855-65.

Schmidt, G., and M. S. Laskowski, 1961. "Phosphatase ester cleavage (survey)," in The enzymes, 2nd Edn. Eds P. D. Boyer, H. Lardy, and K. Myrback (New York, NY: Academic), 3-35.

Shang, C., J. W. B. Stewart, and P. M. Huang, 1992. pH effect on Kinetics of adsorption of organic and inorganic phophates by shortrange Ordered aluminium and iron precipitates. Geoderma 53, 1-14. Doi: 10.1016/0016-7061(92)90017-2.

Smernik, R. J., and W. J. Dougherty, 2007. Identification of phytate in Phosphorus ${ }^{-31}$ nuclear magnetic resonance spectra: the need for spiking. Sci. Soc. Am. J. 71, 1045-1050. Doi: $10.2136 /$ sssaj2006.0295.

Smith, S.E., D.J. Read, 2008. Mycorrhizal Symbiosis, Ed 3. Elsevier and Academic, New York, p 800

Snajdr, J., V. Valaskova, V. Merhautova, J. Herinková, T. Cajthaml, and P. Baldrian, 2008. Spatial variability of enzyme activities and microbial biomass in the Upper layers of Quercus petraea forest soil. Soil Biol. Biochem. 40, 2068-2075. Doi: 10.1016/j.soilbio.2008.01.015.

Spohn, M., and Y.Kuzyakov, 2013. Distribution of microbial- and root-derived Phosphatase activities in the rhizosphere depending on $\mathrm{P}$ availability and C Allocation-Coupling soil zymography with 14C imaging. Soil Biol. Biochem. 67,106-113. Doi: 10.1016/j.soilbio.2013.08.015. 
Spohn, M., A. Ermak, and Y. Kuzyakov, 2013. Microbial gross organic-Phosphorus mineralization can be stimulated by root exudates A 33P isotopic dilution study. Soil Biol. Biochem. 65, 254-263. Doi: 10.1016/j.soilbio.2013.05.028.

Stursova, M., and P. Baldrian, 2011. Effects of soil properties and management On the activity of soil organic matter transforming enzymes and the Quantification of soil bound and free activity. Plant Soil 338, 99-110. Doi: 10.1007/s11104-010-0296-3.

Sudhakar, S.I.D., K.U.I. Munish, K.S. Ashish, A. Mostafa, S. Penna and P.T. Lam-Son, 2018. Cellular and Subcellular Phosphate Transport Machinery in Plants Int. J. Mol. Sci. 2018, 19, 1914.

Sun, S., M. Gu, Y. Cao, X. Huang, X. Zhang, et al. 2012. A constitutive expressed phosphate transporter, OsPht1;1, modulates phosphate uptake and translocation in phosphate-replete rice. Plant Physiol. 159:1571-81.

Svistoonoff, S., A. Creff, M. Reymond, C. Sigoillot-Claude, L. Ricaud, et al. 2007. Root tip contact with low-phosphate media reprograms plant root architecture. Nat. Genet. 39:792-96.

Tabatabai, M. A., 1994. "Soil enzymes," in Methods of Soil Analysis. Part 2. Microbiological and Biochemical Properties, Eds R. W. Weaver, S. Angle, P. Bottomley, D. Bezdicek, S. Smith, A. Tabatabai, and A.Wollum (Madison,WI: Soil Science Society of America Journal), 775-833.

Takabatake, R., S. Hata, M. Taniguchi, H. Kouchi, T. Sugiyama, and K. Izui, 1999. Isolation and characterization of cDNAs encoding mitochondrial phosphate transporters in soybean, maize, rice, and Arabidopsis. Plant Mol. Biol. 40:479-86.

Turner, B.L., and A.B. Leytem, 2004. Phosphorus compounds in sequential extracts of animal manures: chemical speciation and a novel fractionation procedure. Environ Sci Technol 38: 6101-6108 Shen et al. 1004 Plant Physiol .

Turner, B.L., M.J. Papha'zy, P.M. Haygarth, and I.D. McKelvie, 2002. Inositol phosphates in the environment. Philos Trans R Soc Lond B Biol Sci 357: 449-469.

Turner, B.L., A.E. Richardson, and E.J. Mullaney, 2007. Inositol Phosphates: Linking Agriculture and the Environment. CAB International, Wallingford, UK, p 304.

Vacheron, J., G. Desbrosses, M. L. Bouffaud, B. Touraine, Y. Moënne-Loccoz, D. Muller, et al., 2013. Plant growth-promoting rhizobacteria and root system Front. Plant Sci. 4:356. Doi: 10.3389/fpls.2013.00356.

Vance. C.P., 2008. Plants without arbuscular mycorrhizae. In PJ White, JP Hammond, eds, The Ecophysiology of Plant-Phosphorus Interactions. Springer, Dordrecht, The Netherlands, 117 142 .

Vance, C.P., 2010. Quantitative trait loci, epigenetics, sugars, and microRNAs: quaternaries in phosphate acquisition and use. Plant Physiol 154: 582-588

Vance, C.P., C. Uhde-Stone, and D.L. Allan, 2003. Phosphorus acquisition and use: critical adaptations by plants for securing a nonrenewable resource. New Phytol. 157: 423-447.

Versaw, W., and M. Harrison, 2002. A chloroplast phosphate transporter, PHT2;1, influences allocation of phosphate within the plant and phosphate-starvation responses. Plant Cell, 14:1751-66.

Wakelin, S. A., R. A. Warren, P. R. Harvey, and M. H. Ryder, 2004. Phosphate Solubilization by Penicillium spp. closely associated with wheat roots. Biol. Fert. Soils 40, 36-43. Doi: 10.1007/s00374-004-0750-6.

Wang, C., S. Ying, H. Huang, K. Li, P. Wu, and H. Shou, 2009. Involvement of OsSPXI in phosphate homeostasis in rice. Plant J. 57:895-904.

Wang, L., Z. Li, W. Qian, W. Guo, X. Gao, et al., 2011. The Arabidopsis purple acid phosphatase AtPAP10 is predominantly associated with the root surface and plays an important role in plant tolerance to phosphate limitation. Plant Physiol. 157:1283-99.

Wang, L.J., and G.H. Nancollas, 2008. Calcium orthophosphates: crystallization and dissolution. Chem Rev 108: 4628-4669.

Wang, X., X. Yan, and H. Liao, 2010. Genetic improvement for phosphorus efficiency in soybean: a radical approach. Ann. Bot. 106:215-22.

Wasaki, J., H. Maruyama, M. Tanaka, T. Yamamura, H.Dateki, T. Shinano, et al., 2009. Overexpression of the LaSAP2 gene for secretory acid phosphatase in White lupin improves the phosphorus uptake and growth of tobacco plants. Soil Sci. Plant Nut. 55, 107-113. Doi: 10.1111/j.17470765.2008.00329.x. 
Wenbo, P., W.Yaorong, and X. Qi, 2019. Regulation of Ubiquitination Is Central To the Phosphate Starvation Response Article in Trends in Plant Science DOI:10.1016/j.tplants.2019.05.002

Williamson, L.C., S.P.C.P. Ribrioux, A.H .Fitter, and H.M.O. Leyser, 2001. Phosphate availability regulates root system architecture in Arabidopsis. Plant Physiol. 126:875-90.

Wissuwa, M., M. Mazzola, and C. Picard, 2009. Novel approaches in plant breeding for rhizosphererelated traits. Plant Soil 321: 409-430.

Xiao, K., J. Liu, G. Dewbre, M. Harrison, and Z.Y. Wang, 2006. Isolation and characterization of rootspecific phosphate transporter promoters from Medicago truncatula. Plant Biol. 8:439-49

Xu, X., P. E. Thornton, and W. M. Post, 2013. A global analysis of soil microbial Biomass carbon, nitrogen and phosphorus in terrestrial ecosystems. Global Ecol. Biogeogr. 22, 737-749. Doi: 10.1111/geb.12029.

Yadav, R. S., and J. C. Tarafdar, 2003. Phytase of fungi in arid and semi-arid soils And their efficiency in hydrolysing different organic P compounds. Soil Biol. Biochem. 35, 1-7. Doi: 10.1016/S00380717(03)00089-0.

Yan, X., P. Wu, H. Ling, G. Xu, F. Xu, and Q. Zhang, 2006. Plant nutriomics in China: an overview. Ann Bot (Lond) 98: 473-482.

Yang, S.F., and N.E. Hoffman, 1984. Ethylene biosynthesis and its regulation in higher plants. Annu. Rev., Plant Physiol., 35:155-189.

Zhang, F., J. Shen, J. Zhang, Y. Zuo, L. Li, and X. Chen, 2010. Rhizosphere processes and management for improving nutrient use efficiency and crop productivity: implications for China. Adv. Agron., 107: $1-32$. 